\title{
22. INTEGRATION OF SEISMIC REFLECTION, PHYSICAL PROPERTIES, AND DOWNHOLE LOGGING DATA ${ }^{1}$
}

\author{
R.A. Edwards ${ }^{2}$
}

\begin{abstract}
Synthetic seismograms have been derived from downhole logging and physical properties measurements at Sites 959, 960, and 962. Logging data were not available at Site 961. The synthetic seismograms were calculated by convolving the source wavelet with a reflectivity series determined from the acoustic impedance. Seismic reflectors arise where changes in acoustic impedance are encountered because of increases or decreases in either, or both, sonic velocity and bulk density. Where sonic velocity or bulk density logs were not available, these parameters were calculated from resistivity or porosity logs. The agreement between calculated and observed velocities and bulk densities was good considering that large generalizations were made in assuming that the matrix velocity and density of the sediments remained constant throughout the section logged. The calculated synthetic seismograms generally show a good fit to the observed seismic data recorded over the sites. The best results were achieved for Hole 959D, where several individual reflectors could be determined. The most prominent reflector at Site 959, which separates seismically transparent claystones above the acoustic basement from more reflective facies above the reflector, was found to correlate with a decrease in clay content (increase in carbonate cement) at 760 meters below seafloor (mbsf) rather than a lithologic boundary identified from the cores. This reflector, within lithologic Subunit IIC, corresponds to a large increase in both sonic velocity and bulk density, and also represents the upper limit at which significant structural deformation is seen in the cores. The integration of different analyses (seismic, structural, and smear slide analyses) has helped to identify this significant boundary/event, which may otherwise have been missed from core descriptions alone.

Synthetic seismograms calculated for Holes 960A and 962D also modeled the observed seismic data fairly well. In these shallow holes no reflectors above acoustic basement could be identified. The acoustic basement reflection was found to represent at least two individual reflectors at both Sites 960 and 962, which could not be identified individually because of interference of the seismic waves.

The integration of core data to seismic data presented here will provide a good base for any further interpretation of the seismic stratigraphy over the Côte d'Ivoire-Ghana Transform Margin, and the Deep Ivorian Basin in particular.
\end{abstract}

\section{INTRODUCTION}

One of the primary objectives of Ocean Drilling Program (ODP) Leg 159 was to study the tectonic evolution of a transform, or sheared, passive margin. Comparatively little is known about the structure and evolution of transform margins compared to rifted margins. The transform margins of the northern Gulf of Guinea in the equatorial Atlantic have been the subject of several research cruises, and a large database of seismic reflection data has been built up over the last 20 years. Leg 159 aimed to discover the timing and extent of the uplift of the marginal ridge, the degree and type of deformation suffered, and when Africa and South America parted to give fully marine conditions in the equatorial Atlantic. Drilling on the Côte d'Ivoire-Ghana Marginal Ridge (CIGMR) and in the Deep Ivorian Basin (DIB) has provided a record of lithologies, ages, and tectonic events at the drill sites. However, to extrapolate these findings over the entire region of interest requires accurate ties between the lithologies recovered and the seismic reflection profiles passing over the sites before individual reflectors corresponding to facies changes can be confidently traced to greater distances.

The aim of this paper is to provide a tie between seismic reflection data acquired on board the JOIDES Resolution and the cores recovered, using both downhole logging and physical properties data.

Mascle, J., Lohmann, G.P., and Moullade, M. (Eds.), 1998. Proc. ODP, Sci. Results, 159: College Station, TX (Ocean Drilling Program).

${ }^{2}$ Department of Earth Sciences, University of Cambridge, Bullard Laboratories, Madingley Road, Cambridge, CB3 0EZ, United Kingdom. edwards@esc.cam.ac.uk

\section{DATA}

\section{Single-Channel Seismic Data}

Approximately $250 \mathrm{~km}$ of single-channel seismic reflection data was recorded at the start of Leg 159 (Fig. 1). The lines were shot to form figure-eight layouts across Sites 959, 961, and 962 (the three principal proposed sites; IG1, IG2, and IG3). The survey lines were chosen so that one pass over a site coincided with a previously recorded multichannel seismic line, giving further confidence in the exact location of the sites. The data were shot using two $200-\mathrm{in}^{3}$ water guns fired at 12-s intervals and recorded on a single channel using a 100-m hydrophone streamer. The ship's speed was 5-6 kts, giving a shot interval of 30-37 m. Full details of the acquisition parameters are given in Edwards and Shipboard Scientific Party (1996).

The data were recorded digitally in SEGY format, and preliminary processing was conducted on board using the SioSeis processing package. On land further processing was performed using ProMAX processing software. The data were corrected for amplitude losses because of spherical spreading and attenuation using a basic velocity model based on physical properties data. The profiles were then band-pass filtered from 3 to $70 \mathrm{~Hz}$, and neighboring pairs of traces were added to improve the signal to noise ratio. Deconvolution tests with varying parameters made no appreciable improvement in the clarity of the data; therefore, deconvolution was not performed. The data are of fairly poor quality, especially over Sites 961 and 962 (proposed Sites IG2 and IG3), but the signal to noise ratio improves over Site 959. The seismic data have not been migrated.

\section{Physical Properties Data}

Discrete physical properties measurements were made on core samples collected at all four sites. The data of interest in this study are 


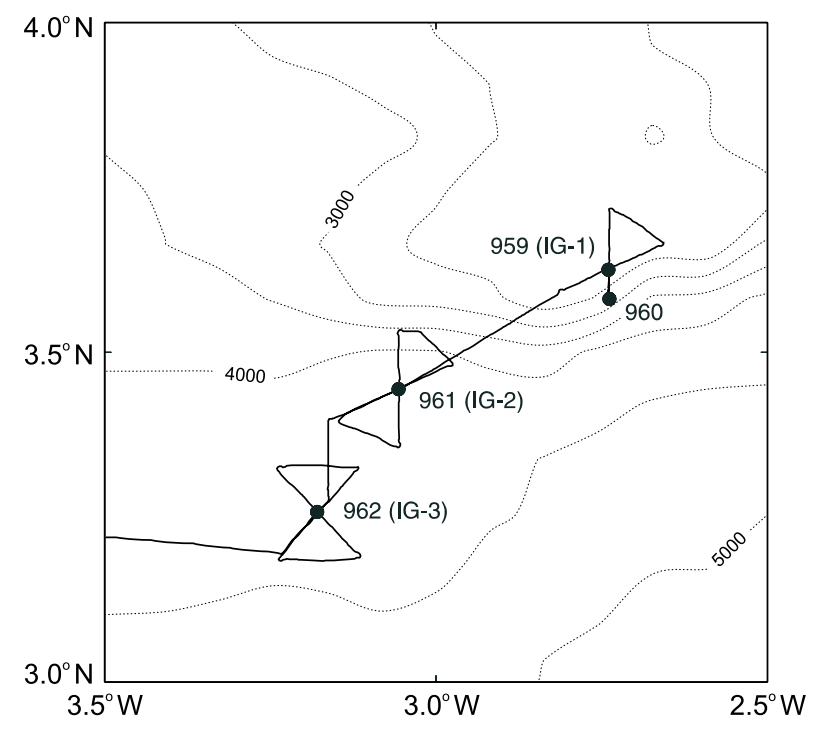

Figure 1. Location map showing the four sites drilled during Leg 159 and the single-channel seismic reflection profiles (solid black line) collected at the beginning of the leg.

velocity measurements and bulk density. Discrete measurements of $P$-wave velocity were made using a Digital Sound Velocimeter (DSV1) and a Hamilton Frame Velocimeter (DSV3). Both methods were used in soft sediments, but only the Hamilton Frame Velocimeter was used in lithified sediments. In soft sediments, the two transducers of DSV1 were inserted into the sediment along the length of the split core (the vertical direction), while DSV3 was used to measure the velocity across the core in the horizontal direction. In harder sediments, samples were cut into cubes using a double-bladed diamond saw and the sample thickness measured using a pair of 500kHz Linear Variable Displacement Transducers (LVDT), which are attached to the transducers of DSV3. Successful measurement using DSV3 requires consolidated samples, and therefore, sample selection tends to bias towards more lithified samples from the core. Correspondingly the velocities measured may overestimate the true downhole velocities. The velocities were corrected to in situ temperature and pressure following the equations of Wyllie at al. (1956) and Wilson (1960). Velocity measurements were taken in the vertical (along the core) and two orthogonal horizontal directions. Comparison of the three measurements shows anisotropy at all four sites, with horizontal velocities generally being slightly faster than vertical ones. Accordingly, only vertical velocity measurements were used to compare these data to the seismics.

Bulk densities were determined in the physical properties lab by dividing the total wet mass of the sample by the total wet volume. Sample mass was determined using a Scitech electronic balance, with a precision of $\pm 0.01 \mathrm{~g}$, while a Quantchrome Penta-Pycnometer was more often used to determine the sample's volume. The Quantchrome Penta-Pycnometer measures to a precision of $\pm 0.02 \mathrm{~cm}^{3}$.

\section{Editing of Physical Properties Data}

As discussed above, the physical properties velocimetry data were edited to select measurements made in the vertical direction only. This removed the possible effects of any seismic anisotropy in the sediments. For Site 959, discrete measurements of velocity and bulk density were made on the core every $2-10 \mathrm{~m}$. The data were smoothed over $15 \mathrm{~m}$ using a moving boxcar (mean) filter and resampled with a sample interval of $5 \mathrm{~m}$.

\section{Downhole Logging Data}

Unfortunately, because of poor hole conditions, the full range of downhole logs was not available at all four sites. Table 1 shows the available logging data that is relevant to this study. In Hole 959D the Quad combination tool string (combined seismic stratigraphic and lithoporosity tool strings) was deployed, collecting sonic velocity, resistivity, neutron porosity, and lithodensity data from 395 to 1081 meters below seafloor (mbsf). Despite borehole washout near the top and bottom of the logged interval, the data from Hole 959D are generally of excellent quality.

The Sonic Digital Tool (SDT) contained two broadband (5-18 $\mathrm{kHz})$ piezoelectric transmitters spaced $2 \mathrm{ft}(0.610 \mathrm{~m})$ apart and two receivers positioned $3 \mathrm{ft}(0.914 \mathrm{~m})$ and $5 \mathrm{ft}(1.524 \mathrm{~m})$ above the upper transmitter. This provided raw traveltime measurements over 0.914-, 1.524-, and 2.134-m transducer separations. The traveltimes were then converted to velocities and the logs edited for any obviously erroneous values. For this study, short-spaced velocity measurements were used. The sonic tool has a vertical resolution of approximately $0.6 \mathrm{~m}$.

Electrical resistivity data were collected using the Dual Induction Resistivity Tool (DITE) that provides three resistivity measurements at different depths within the formation. The tool creates alternating currents through transmitter coils, which induce secondary currents (proportional to conductivity) in the formation. These are then measured by receiver coils, and conductivity converted to resistivity. For this study, data were taken from the spherically focused resistivity instrument, which gives higher vertical resolution. The vertical resolution is about $0.76 \mathrm{~m}$ and the depth of investigation is approximately $0.38 \mathrm{~m}$.

Neutron porosity was measured using the Dual Porosity Compensated Neutron Tool (CNT-G). A radioactive source emits high energy neutrons into the formation. The neutrons are slowed and captured by collisions with hydrogen atomic nuclei residing largely in water molecules. The number of neutrons detected at the tool's receiver is, therefore, related to the porosity of the formation. The vertical resolution of the CNT-G tool is $0.55 \mathrm{~m}$.

The High-temperature Lithodensity Tool (HLDT) used a cesium137 source of gamma rays to measure formation bulk density. The source and two detectors are pressed against the borehole wall. Density determination is based on the Compton scattering of gamma rays within the formation, which is related to electron density. The electron density is then converted to bulk density. The vertical resolution is approximately $0.4 \mathrm{~m}$.

In Hole 960A a modified Quad tool string was deployed collecting sonic velocity, density, resistivity, and porosity data from 73 to 361 mbsf. Logging in this hole was severely hampered by borehole washout, which resulted in the hole diameter exceeding 17 in (the maximum caliper range) for most of its depth. The wide borehole diameter degrades the sonic logging and induces "cycle skipping," where the receivers pick incorrect first-arrival times used in the velocity calculation. The density data are also downgraded by the tool measuring a combination of formation and seawater densities giving an overall density value that is anomalously low. The resistivity data are affected to a much lesser degree by borehole diameter. Despite these problems, the density data from this hole appear to be of reasonable quality. Only the seismic data cannot be used without further processing of the full waveform sonic data.

Because of technical problems in Hole 961A and poor hole conditions in Hole 961B, no logging data were acquired at Site 961. Poor hole conditions were also encountered at Site 962, but a modified seismic stratigraphic tool string was run in Hole 962D. The nuclear source was removed from the high-temperature lithodensity tool string; therefore, only sonic and resistivity data were collected from 162 to 328 mbsf. Borehole washout was also a problem at this hole, 
Table 1. The downhole logging data relevant to this study available at Sites 959, 960, 961, and 962.

\begin{tabular}{|c|c|c|c|}
\hline Hole & $\begin{array}{l}\text { Interval } \\
\text { logged }\end{array}$ & Logs available & Comments \\
\hline 959D & 395-1081 mbsf & $\begin{array}{l}\text { SDT (Sonic Digital Tool) } \\
\text { HLDT (High-temperature Lithodensity Tool) } \\
\text { DITE (Dual Induction Resistivity Tool) } \\
\text { CNT-G (Dual Porosity Compensated Neutron Tool) }\end{array}$ & \\
\hline $960 \mathrm{~A}$ & 73-361 mbsf & $\begin{array}{l}\text { SDT (Sonic Digital Tool) } \\
\text { HLDT (High-temperature Lithodensity Tool) } \\
\text { DITE (Dual Induction Resistivity Tool) } \\
\text { CNT-G (Dual Porosity Compensated Neutron Tool) }\end{array}$ & Sonic and density logs badly affected by borehole washout \\
\hline $962 \mathrm{D}$ & $162-328 \mathrm{mbsf}$ & $\begin{array}{l}\text { SDT (Sonic Digital Tool) } \\
\text { DITE (Dual Induction Resistivity Tool) }\end{array}$ & Sonic log affected by borehole washout \\
\hline
\end{tabular}

and the hole diameter exceeded 14 in for most of the measured interval. The sonic data are very noisy and have not been further processed, but the resistivity data are of good quality despite the poor hole conditions.

\section{Editing of Downhole Logs}

All of the downhole logs used in this study contained high frequency noise expressed as rapidly fluctuating higher and lower values. These short-term fluctuations were removed using a 2-m moving boxcar (mean) filter. The logs were then resampled with a $0.5-\mathrm{m}$ interval. This provided standardization to allow comparison and correlation between different logs.

\section{SITE 959}

Site 959 is located to the north of the crest of the CIGMR, in the Deep Ivorian Basin. The site was crossed by two lines during the single-channel seismic survey at the beginning of the leg; one of the lines, running north-south, is coincident with multichannel seismic Line MT02 (Figs. 1, 2A). The second line is parallel to the crest of the CIGMR (Fig. 2B). Hole 959D reached a total depth of 1158.9 mbsf, ending in Lower Cretaceous quartz sandstones, claystones, and siltstones, which represent acoustic basement. The overlying sediments are mostly shallow dipping and have suffered little deformation.

\section{Synthetic Seismograms}

At Hole 959D, both sonic velocity and bulk density logs were available (Table 1) for the calculation of synthetic seismograms. However, the logged interval only corresponded to 395-1081 mbsf. To overcome this problem, discrete core measurements of velocity and bulk density from the top $400 \mathrm{~m}$ of Hole 959A were merged with the logging data from Hole 959D to provide complete coverage from 0 to 1036 mbsf. The velocity and density logs were converted from depth to two-way traveltime (TWT) using the velocity log to enable comparison with the seismic records. The logs were resampled to a sample interval of $2 \mathrm{~ms}$ (Fig. 3). A 2-ms sample interval (Nyquist frequency $250 \mathrm{~Hz}$ ) was chosen to prevent an alias of the synthetic seismogram, the dominant frequency of the seismic source being $40 \mathrm{~Hz}$. The velocity and density logs were then multiplied together to give a $\log$ of acoustic impedance (Fig. 3). From the acoustic impedance a reflectivity series was calculated using the relationship

$$
R=\frac{\left(Z_{i+1}-Z_{i}\right)}{\left(Z_{i+1}+Z_{i}\right)},
$$

where $R$ is the reflection coefficient at interface $i$, and $Z_{i}$ and $Z_{i+1}$ are the acoustic impedances above and below the interface. The calcula- tion was simplified by assuming only vertical travel of seismic energy and horizontal interfaces. Also, diffractions, multiples, and energy losses such as spherical spreading and attenuation were ignored. Reflection coefficients were plotted against TWT. To produce a synthetic seismogram the reflectivity series was then convolved with a source wavelet. The direct seismic source was not recorded during the seismic survey at the start of the leg; therefore, a representative, clean, seafloor reflection was picked from the observed seismic profiles and used as the source wavelet. Because the reflectivity series starts immediately below the seafloor, a seafloor reflection is not included in the synthetic seismogram. The synthetic seismogram was plotted with positive polarity so that positive reflections (increases in acoustic impedance) are plotted as black peaks. This convention has also been used in the display of the observed seismic data. The synthetic trace was repeated five times (Fig. 3).

\section{Comparison of the Synthetic Seismogram with the Recorded Seismic Data}

Figure 4 shows the synthetic seismogram calculated from the downhole logging and core physical properties data spliced into the two seismic lines crossing Site 959 (Lines IG1-1 and IG1-2) at the correct locations. The general fit between the synthetic and recorded seismic data is good. The major reflectors above the acoustic basement have been reproduced well. The overall fit is slightly better on Line IG1-1 than on Line IG1-2, suggesting that Line IG1-2 may not cross Site 959 exactly.

The shallowest reflector, at $0.24 \mathrm{~s}$ TWT below the seabed, can be attributed to a sharp decrease in bulk density, although little variation is seen in the velocity data. This corresponds to a depth of $180 \mathrm{mbsf}$, and the transition from the nannofossil/foraminifer oozes of lithologic Subunit IB to the diatomite with nannofossil chalk of lithologic Subunit IIA (Mascle, Lohmann, Clift, et al., 1996). This event can be seen as a weak reflector on seismic Line IG1-2 but is not discernible on Line IG1-1. The second reflector, at $0.46 \mathrm{~s}$ TWT below the seabed, marks the top of a 0.2-s-TWT-thick package of more reflective facies compared to the acoustically transparent units above. This corresponds to the base of lithologic Subunit IIA, Subunit IIB, and the top of Subunit IIC. Subunit IIB is composed of black cherts and claystones, the contacts of which with the diatomite above and porcellanite below will cause reflections. As Subunit IIB is only 24 to $57 \mathrm{~m}$ thick, reflections from its upper and lower surface cannot be identified separately. On seismic Line IG1-2, this reflector has a discontinuous, broken appearance, suggesting that the chert layer may be faulted. The strongest, most laterally continuous reflector seen on Lines IG1-1 and IG1-2 occurs at $0.88 \mathrm{~s}$ TWT below the seabed at Site 959. This separates the more reflective facies above from the acoustically transparent unit below. Based on the logs, this reflector corresponds to a depth of $740 \mathrm{mbsf}$, that is, within lithologic Subunit IIC (the base of which lies at $812 \mathrm{mbsf}$ ). From the lithologic column (Mascle, Lohmann, Clift, et al., 1996) the cause of this reflector is somewhat 

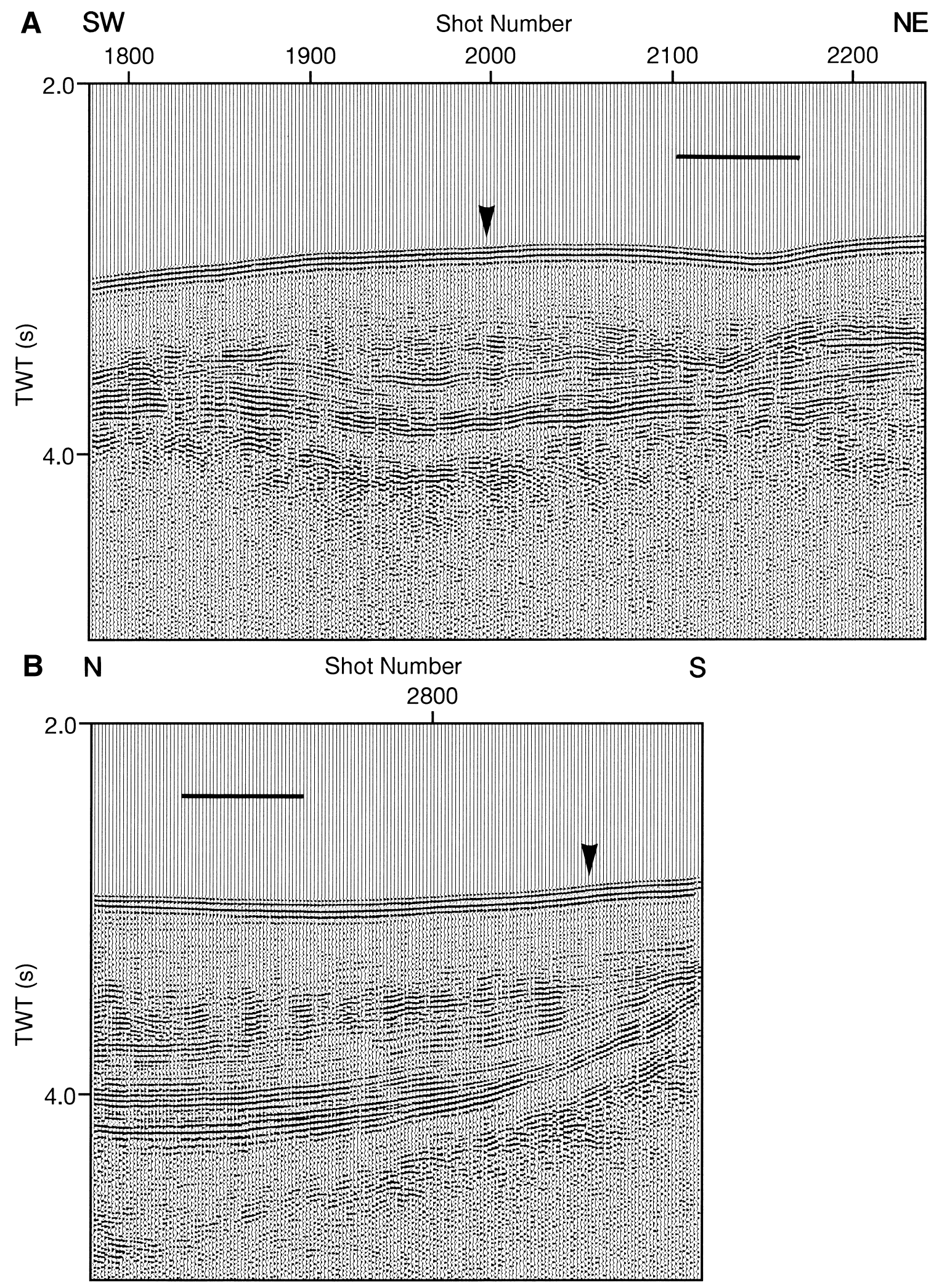

Figure 2. Single-channel seismic reflection profiles collected at the beginning of Leg 159 over Site 959. For processing details see text. Arrow above seabed marks the location of Site 959. A. Line IG1-1. B. Line IG1-2. For line locations see Figure 1. Horizontal scale bar $=5 \mathrm{~km}$. 


\section{Site 959}

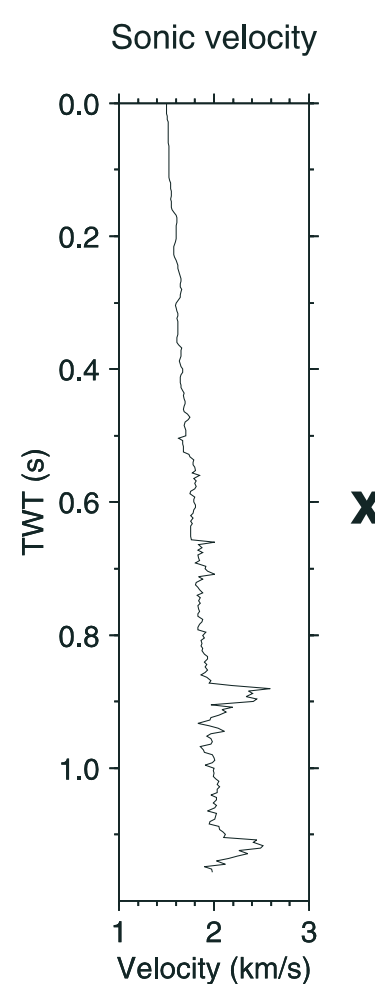

Bulk density

Acoustic impedance

Reflection coefficient

Synthetic seismogram
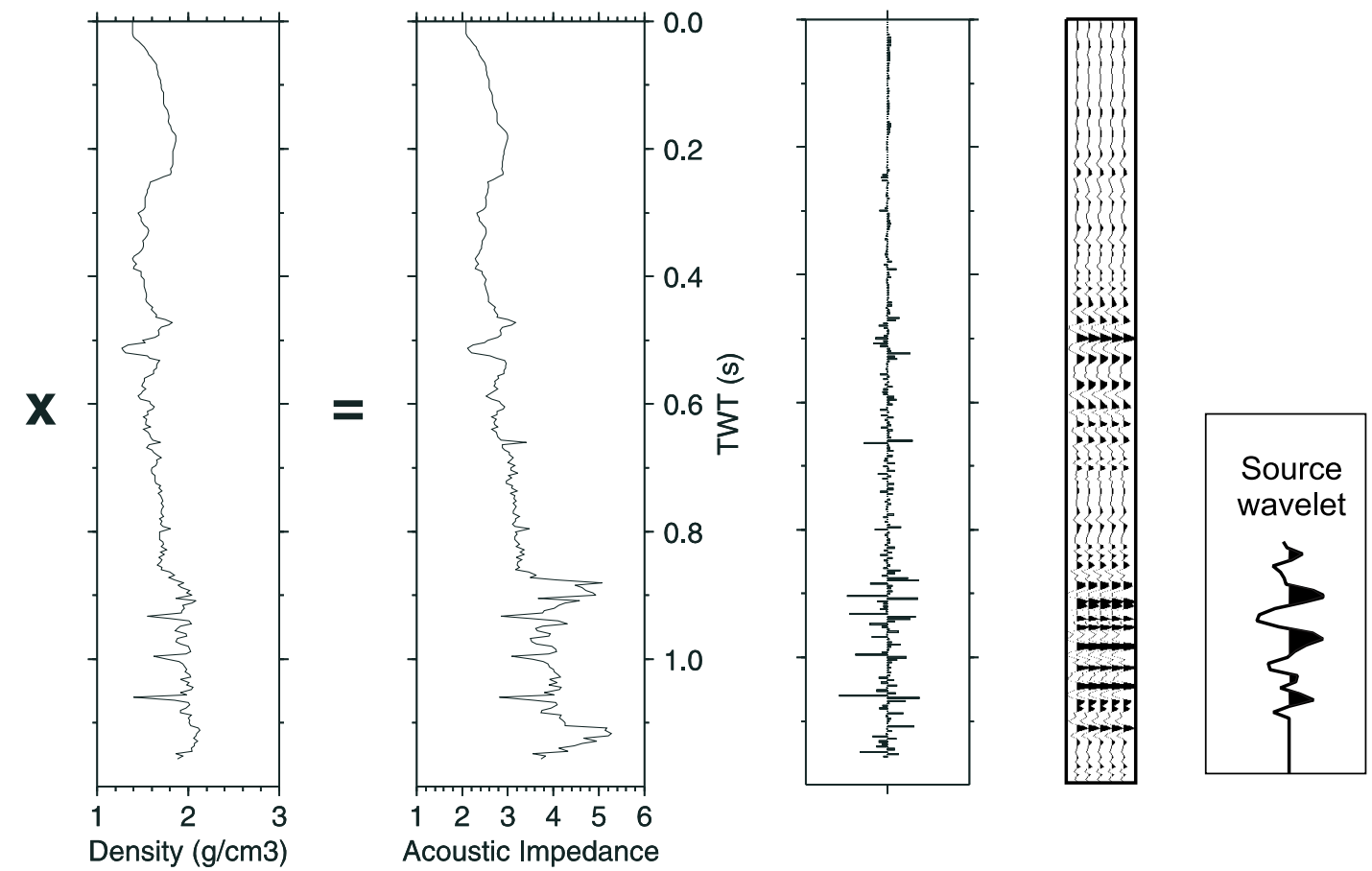

Figure 3. Sonic velocity and bulk density logs from Hole 959D. The logs are derived from combining downhole logging and physical properties (above $400 \mathrm{mbsf}$ ) data. Multiplication of these logs gives the log of acoustic impedance from which the reflection coefficient and synthetic seismogram are calculated. The source wavelet (derived from the seafloor reflection) is shown in the bottom right-hand corner. The wavelet length is $150 \mathrm{~ms}$.

enigmatic, but examination of a plot of percentage of clay minerals (from smear slide analysis) against depth (Fig. 5) shows a decrease to zero clay content at approximately $740 \mathrm{mbsf}$. The decrease in clay content is accompanied by an increase in carbonate content, expressed as nannofossil chalk. The increase in carbonate content may mean that these sediments are more cemented, leading to the large increase in velocity, on the order of $0.6 \mathrm{~km} / \mathrm{s}$, seen in the downhole log. At the top of Unit III the velocity decreases again to a value around $2.0 \mathrm{~km} / \mathrm{s}$. From the structural data at Site 959, it appears that this depth also defines the uppermost limit where major structural deformation was observed in the cores (Pickett, Chap. 1, this volume).

Below $0.88 \mathrm{~s}$ TWT below the seabed $(740 \mathrm{mbsf})$, the fit between the synthetic seismogram and the observed seismic data is not as good. The synthetic contains several bright reflectors between 0.9 and $1.1 \mathrm{~s}$ TWT, a region that is acoustically transparent on the seismic lines. This corresponds to the black claystones of lithologic Unit III. From the velocity and bulk density logs it can be seen that these reflections in the synthetic seismogram arise from sharp decreases in bulk density within this region. Examination of the caliper log from Hole 959D does not show any strong correlation between these lowdensity spikes and borehole washouts (a cause of anomalously lowdensity measurements), yet there is also no obvious explanation for their presence from the lithologic column and core descriptions (Mascle, Lohmann, Clift, et al., 1996). Because the logging data stops at a depth of $1036 \mathrm{mbsf}$, it was not possible to effectively model the hyperbolic reflection that corresponds to acoustic basement.

In an attempt to improve the fit of the synthetic seismogram to the observed data over the bottom part of the section, a new synthetic was made using the sonic velocity data only. In this case, the reflection coefficient series was calculated using velocities alone rather than acoustic impedance. The results are shown in Figure 6 compared to Lines IG1-1 and IG1-2. Figure 6 data show an improvement to the fit in the lower part of the section, where the synthetic shows a better match to the acoustically transparent unit corresponding to the black claystones of lithologic Unit III. However, in the upper part of the section, the fit has been degraded by the omission of the bulk density data. In particular, the reflection at $0.46 \mathrm{~s}$ TWT below the seabed is now poorly modeled.

\section{Integration of Resistivity, Porosity, and Velocity Data}

The above section has shown that synthetic seismograms can still be generated even if velocity or bulk density data are not available, although the results may be less effective. Although the full suite of logs was available for Site 959, the remaining three sites drilled do not have as good downhole logging data coverage (Table 1). In these cases, it should be possible to derive "pseudo-" velocity and density $\operatorname{logs}$ from the other logs that are available, most notably resistivity and porosity logs. Resistivity logs, in particular, are much less likely to be adversely affected by poor borehole conditions. The derivation of porosity and velocity from the resistivity log was examined for Hole 959D, where velocity and porosity logs were also recorded, giving the opportunity for comparison between the measured and calculated porosities and velocities.

As most rock-forming minerals are extremely poor conductors of electricity, the conductivity of a formation is usually controlled primarily by the fluids contained within the rock's pores. Conductivity in these cases (electrolytic conduction) is dependent on the amount of fluid contained within the rock, the conductivity of the fluid itself, and the degree of connection and distribution of the pore spaces. Con- 
A

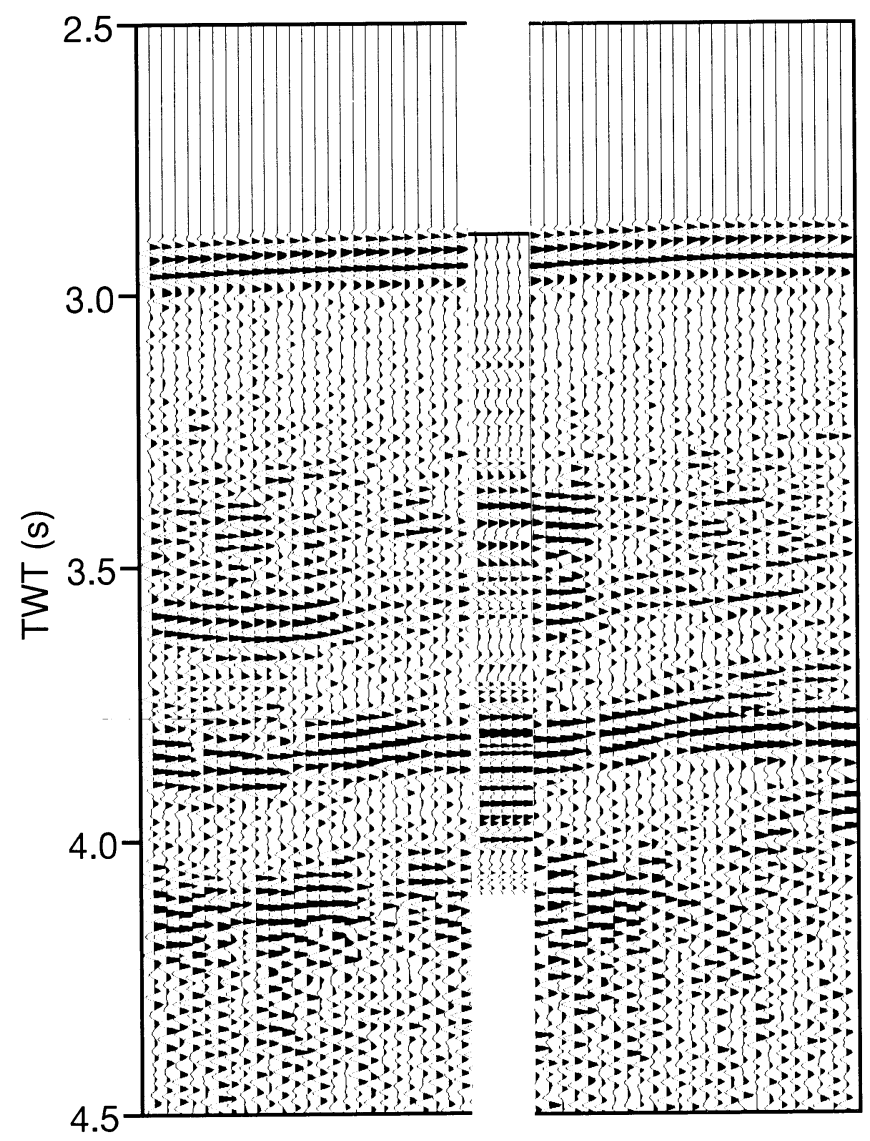

B Site 959

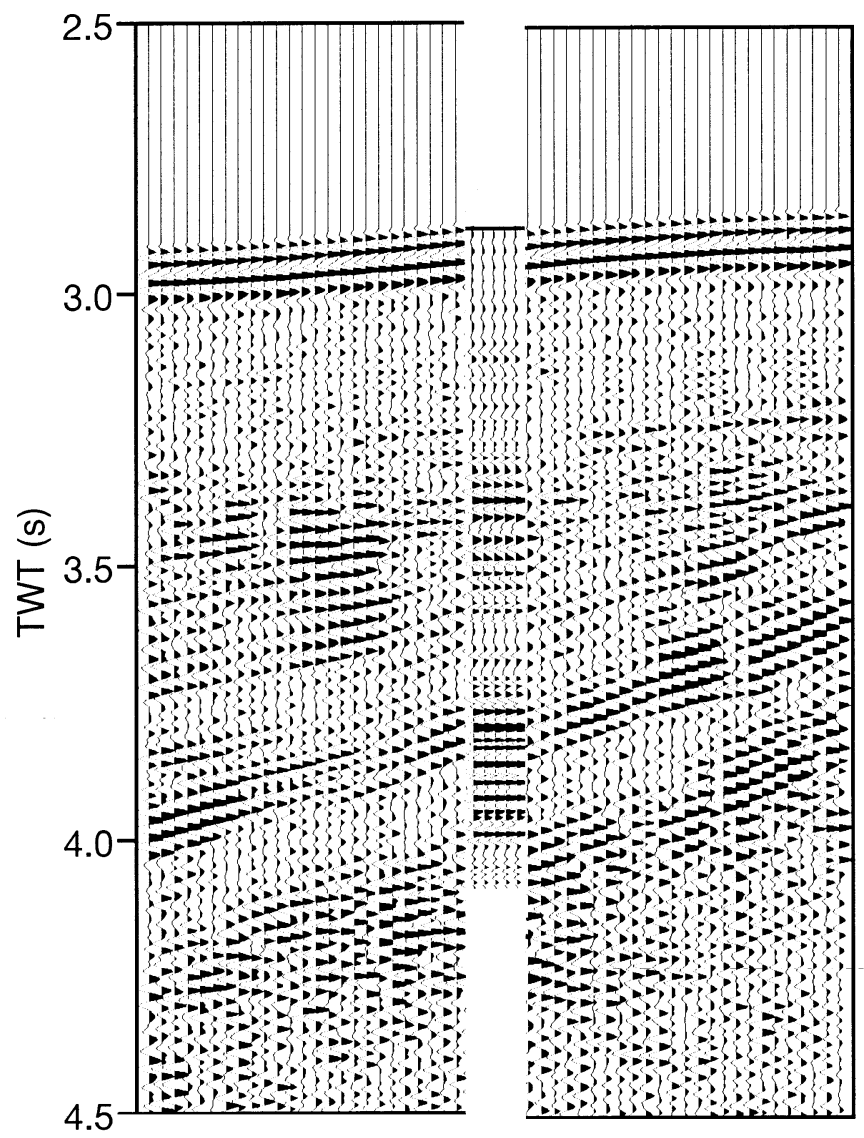

Figure 4. Synthetic seismogram calculated for Hole 959D spliced into the crossing single-channel seismic reflection profiles at the appropriate locations. The seabed reflection is not included in the synthetic seismogram. A. Line IG1-1. B. Line IG1-2.

ductivity (and hence resistivity) is, therefore, dependent largely on the rock's porosity. Resistivity is often expressed as Formation Factor $(F F)$,

$$
F F=\frac{R_{b}}{R_{f}},
$$

where $R_{b}$ is the resistivity of the formation and $R_{f}$ is the resistivity of the pore fluids. This removes the dependence of the resistivity of the formation as a whole on the resistivity of the pore fluids. Formation Factor is unitless. The $F F$ can also be related to porosity $(\phi)$ by (Archie, 1942)

$$
F F=\frac{1}{\phi^{m}},
$$

where $m$ is a constant related to the degree of cementation of the formation or, for unconsolidated rocks, the shape of the grains. For sediments with well connected interparticle porosity a value of $m=2$ is usually appropriate. Alternately, the expression can be written (Winsauer et al., 1952)

$$
F F=\frac{a}{\phi^{m}}
$$

where $a$ is a constant that depends on sediment type. The porosity of a formation can, therefore, be derived from the resistivity by

$$
\phi=\left(\frac{a R_{f}}{R_{b}}\right)^{1 / 2} .
$$

If the pore fluids alone are responsible for conduction, then $a=1$. The pore fluid can be assumed to be seawater, which has a resistivity of $0.3 \Omega \mathrm{m}$ at $4^{\circ} \mathrm{C}$. The resistivity of seawater is dependent on temperature as (von Herzen et al., 1983)

$$
\text { Conductivity, } \delta=3+\frac{\mathrm{T}}{10} \text {, }
$$

where $T$ is the temperature in degrees Celsius. The conductivity increases with temperature, and hence the resistivity decreases. At Hole 959D, temperature measurements were made to $540 \mathrm{mbsf}$, using the Lamont-Doherty Temperature Logging Tool, where a maximum temperature of $22.5^{\circ} \mathrm{C}$ was recorded. Because temperatures were not recorded over the greater part of the logged hole, no attempt was made to correct for temperature against depth. However, an average borehole temperature of $30^{\circ} \mathrm{C}$ was initially assumed. This reduces the resistivity of the seawater filling the pore spaces to 0.167 $\Omega \mathrm{m}$. Assuming $a=1$, and $m=2$, porosity was calculated from the resistivity log and compared to the observed porosity. It was found that the best fit was achieved using $a \times \mathrm{R}_{f}=0.15$ (Fig. 7). Although this fit is excellent for the upper part of the logged section (396$750 \mathrm{mbsf}$ ), the calculated porosities are slightly too low for the lower half of the section. A better fit could be achieved below $750 \mathrm{mbsf}$ by using $a \times \mathrm{R}_{f}=0.2$, implying that the pore fluids in this region (which corresponds to the black claystones) are more resistive (less saline), or $a>1.0$. 

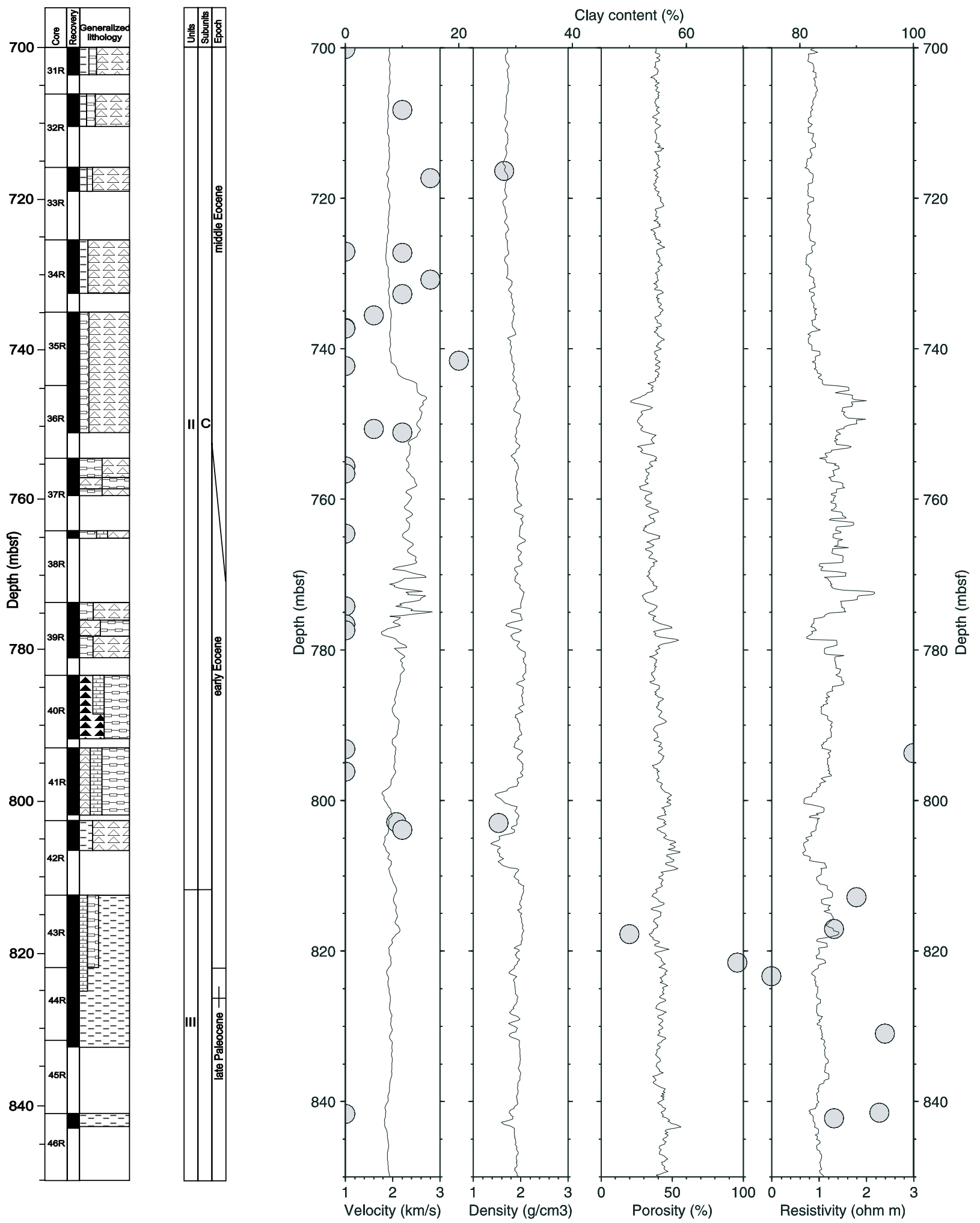

Figure 5. Hole 959D, 700-850 mbsf. Velocity, bulk density, porosity, and resistivity logs showing the log responses to variations in clay content. Clay content from smear slide analyses is shown by the shaded circles and plotted along the top axis. 
A

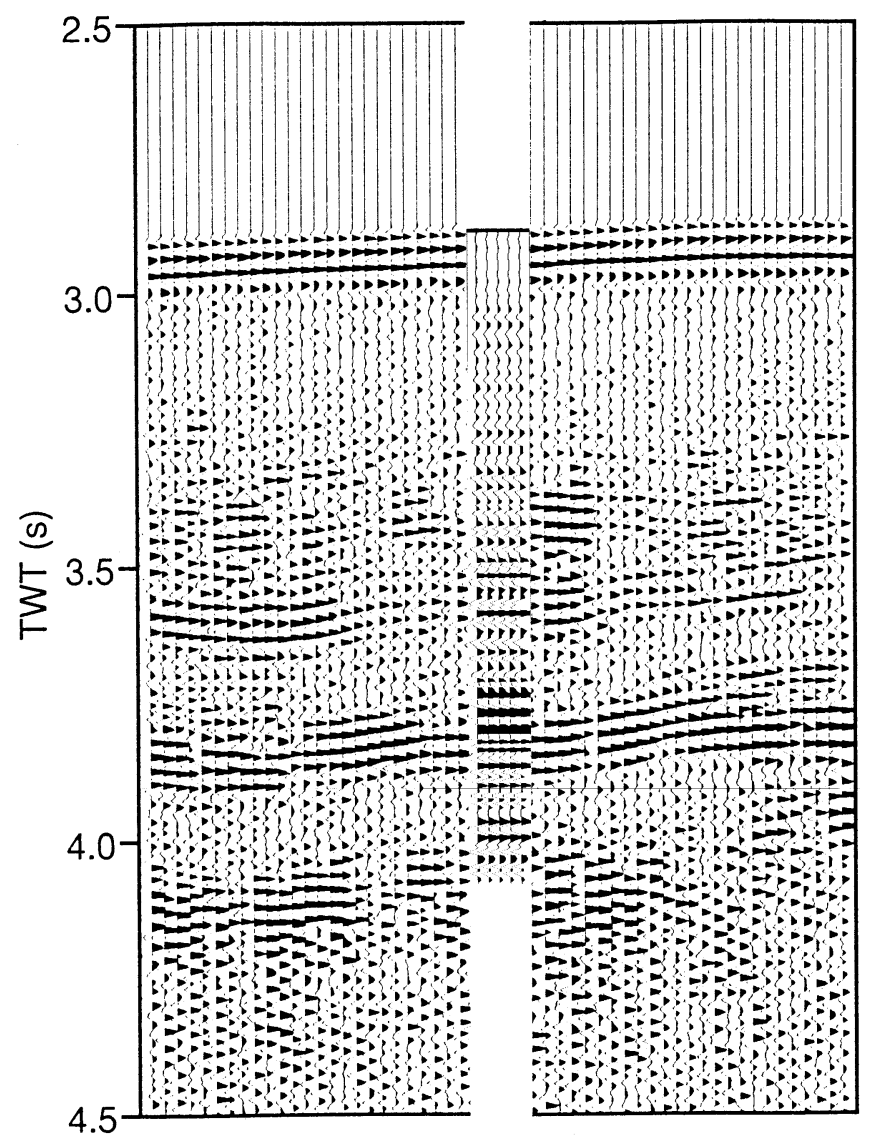

B

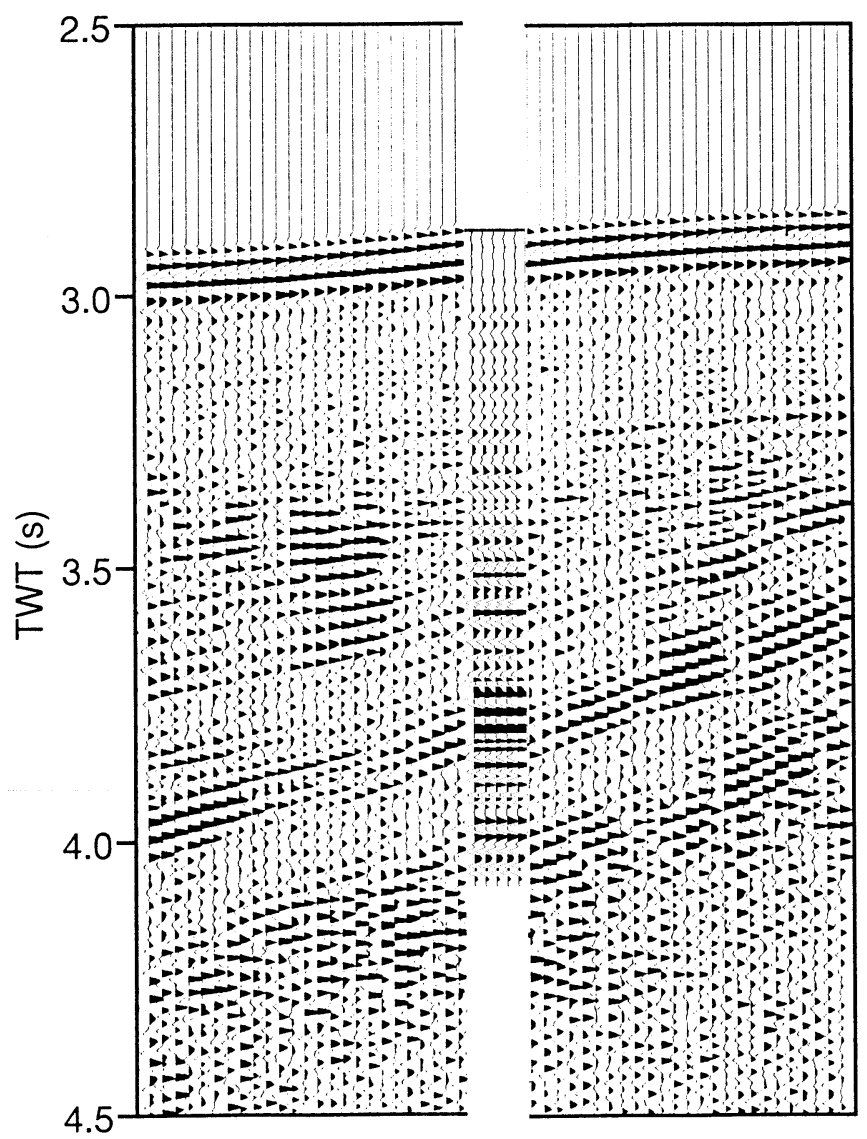

Figure 6. Synthetic seismogram calculated for Hole 959D using velocity data only (instead of acoustic impedance) and spliced into the crossing single-channel seismic reflection profiles at the appropriate locations. The seabed reflection is not included in the synthetic seismogram. A. Line IG1-1. B. Line IG1-2.

Once the porosity of the sediments had been calculated, the sonic velocity could be derived. The relationship between porosity and velocity is usually described using equations by Wyllie et al. (1956) or Wood (1941). The time-average equation of Wyllie et al. (1956) assumes that the traveltime of sound through a porous rock is equal to the time spent traveling through the fluid in the rock plus the time spent traveling through the rock grains, where

$$
\frac{1}{V_{p}}=\frac{\phi}{V_{w}}+\frac{(1-\phi)}{V_{g}},
$$

and $V_{p}$ is the velocity of the whole rock, $V_{w}$ is the velocity of the pore fluid, $V_{g}$ is the velocity of the grains, and $\phi$ is the porosity. Although Wyllie's equation is accurate for porosities less than $25 \%$, it overestimates velocities for higher porosities. This may, in part, be because the equation considers the velocities of the mineral grains rather than the rock matrix. The matrix velocity is generally slightly lower than the grain velocity, especially for higher porosities. The alternative equation from Wood (1941) gives

$$
\frac{1}{\left(\rho_{b} V_{p}^{2}\right)}=\frac{\phi}{\left(\rho_{w} V_{w}^{2}\right)}+\frac{(1-\phi)}{\left(\rho_{g} V_{g}^{2}\right)},
$$

where $\phi$ is the porosity, $\rho_{b}$ and $V_{p}$ are the bulk density and $P$-wave velocity of the rock, $\rho_{w}$ and $V_{w}$ are the density and velocity of the pore fluids, and $\rho_{g}$ and $V_{g}$ are the density and velocity of the grains. Wood's equation tends to predict much lower velocities than Wyllie et al.'s (1956) equation and is most accurate for high (>60\%) porosities. In this study, the grain velocity and grain density in the above two equations have been substituted by the matrix velocity and matrix density as this may be expected to give more accurate results.

Both of these equations depend on the velocity of the matrix of the sediment, an unknown value. To give an indication of a suitable value for the matrix velocity, a series of velocity-porosity curves was calculated for both Wood's (1941) and Wyllie et al.'s (1956) equations using matrix velocities of $2.0,3.0,4.0$, and $5.0 \mathrm{~km} / \mathrm{s}$, and compared to a plot of the observed porosities and velocities (Fig. 8). For Wood's equation, the bulk density was taken to be $1.74 \mathrm{~g} \mathrm{~cm}^{-3}$, and the matrix density $2.56 \mathrm{~g} \mathrm{~cm}^{-3}$. These values were determined by averaging the physical properties bulk density and grain density data measured in Holes 959A and 959D. The velocity and density of the pore fluids were set at $1.50 \mathrm{~km} / \mathrm{s}$ and $1.03 \mathrm{~g} \mathrm{~cm}^{-3}$, respectively. From Figure 8, it can be seen that neither the Wood nor Wyllie et al. velocity-porosity curves fit the observed data. In the following plots a matrix velocity of $3.0 \mathrm{~km} / \mathrm{s}$ was assumed. Obviously this is a major simplification, as the matrix velocity will vary for different lithologies.

Figure 9A shows the observed velocity and the velocity calculated using the methods of both Wood and Wyllie et al. As expected, the velocities calculated using the equation of Wood (1941) are lower than the observed velocity, and the velocities calculated using the equation of Wyllie et al. (1956) are higher than those measured. Nobes et al. (1986) found that a weighted average of the Wood velocities $\left(V_{\text {Wood }}\right)$ and the Wyllie et al. velocities $\left(V_{\text {Wyllie }}\right)$ gave a good result, using 
Hole 959D

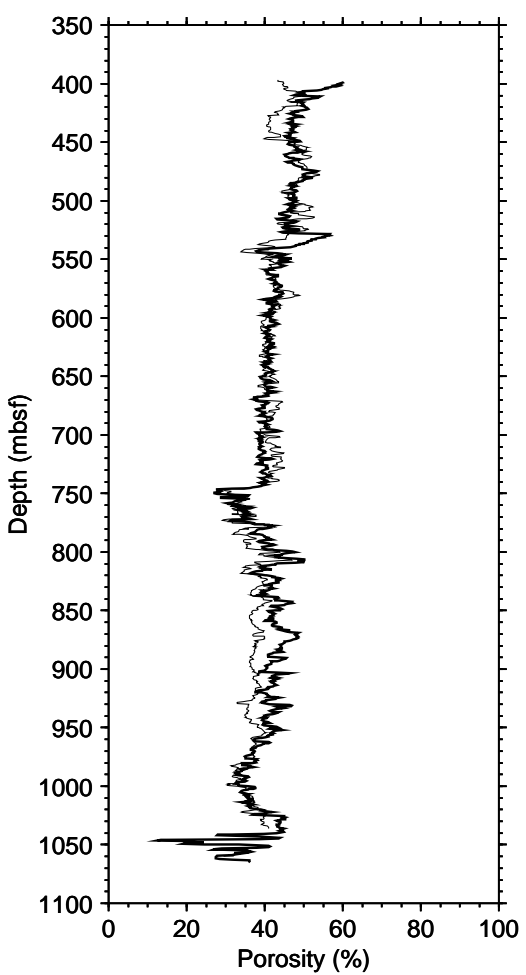

Figure 7. Observed porosity log from Hole 959D (bold line) and the porosity calculated from the resistivity log (thin line) using Winsauer et al.'s (1952) formula.

$$
\frac{1}{V_{p}}=\frac{\phi}{V_{\text {Wood }}}+\frac{(1-\phi)}{V_{\text {Wyllie }}}
$$

The averaged velocity $\left(V_{p}\right)$ shows a much better fit to the observed data than either $V_{\text {Wood }}$ or $V_{\text {Wyllie }}$ (Fig. 9B), although the region of increased velocity starting at $740 \mathrm{mbsf}$ is poorly reproduced. This probably reflects the limitations of assuming a constant matrix velocity, suggesting in this region the matrix velocity should be higher.

Bulk density $\left(\rho_{b}\right)$ can also be related to porosity $(\phi)$ by

$$
\rho_{b}=\rho_{w} \phi+\rho_{g}(1-\phi),
$$

where $\rho_{w}$ is the density of the pore fluids and $\rho_{g}$ is the density of the rock matrix (grains) (Nobes et al., 1986). As above, pore fluid and matrix densities of $1.03 \mathrm{~g} \mathrm{~cm}^{-3}$ and $2.56 \mathrm{~g} \mathrm{~cm}^{-3}$ were assumed to calculate the bulk density of the sediments in Hole 959D from the "pseudo-" porosity log (derived from the resistivity $\log$ ). The calculated bulk densities were then compared to the observed bulk densities (Fig. 10). Figure 10 shows a good fit between the observed and calculated bulk densities below 770 mbsf, although above this depth the calculated bulk densities are consistently too high. This is probably a result of a using an average matrix density for the whole column, the value of which may be too high for the oozes, chalks, and porcellanites that make up the top $400 \mathrm{~m}$ of the interval logged. It is worth noting that the large decreases in the observed bulk density at approximately 800,870 , and $930 \mathrm{mbsf}$, which gave rise to reflections on the synthetic seismogram and were not well matched by the observed seismic data (Fig. 4), are absent from the calculated bulk density log. This suggests that these low values may indeed be spurious.

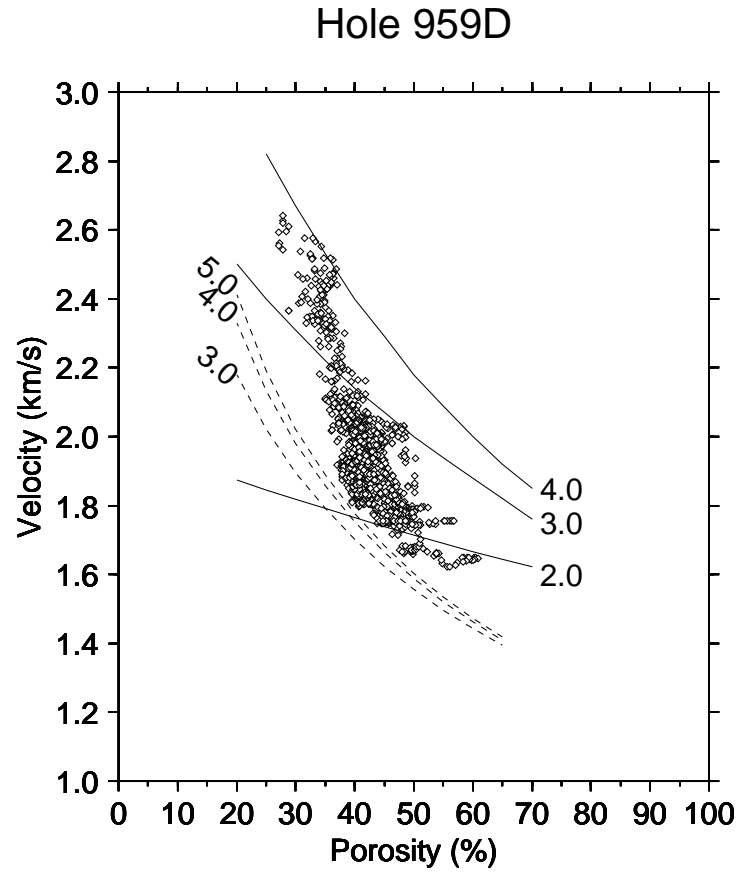

Figure 8. Plot of velocity against porosity from downhole logs at Hole 959D (open diamonds). Solid lines correspond to the velocity-porosity relationship according to the formula of Wyllie et al. (1956). Numbers 2.0 to 4.0 show the matrix velocity used in the calculation. The pore fluid velocity was assumed to be $1.50 \mathrm{~km} \mathrm{~s}^{-1}$. Dashed lines show the velocity-porosity relationship according to the formula of Wood (1941). Pore fluid velocity and density were assumed to be $1.50 \mathrm{~km} \mathrm{~s}^{-1}$ and $1.03 \mathrm{~g} \mathrm{~cm}^{-3}$ respectively, while the matrix density was assumed to be $2.56 \mathrm{~g} \mathrm{~cm}^{-3}$ and the bulk density $1.74 \mathrm{~g}$ $\mathrm{cm}^{-3}$. Numbers 3.0 to 5.0 show the matrix velocity used in the calculation.

\section{SITE 960}

Site 960 is located due south of Site 595 (Fig. 1), on the crest of the CIGMR. Although this site was not among the three primary sites originally proposed, it was drilled to document seismic Unit A (from Mascle, Lohmann, Clift, et al., 1996), which had not been penetrated in Hole 959D. As this site was not one of the primary objectives, single-channel seismic data were not collected over the site at the beginning of the leg. However, multichannel seismic Lines MT02 and MT05 (Basile et al., 1996) do cross the site. The seismic data show a thin veneer of sediment overlying acoustic basement.

Because of poor hole conditions, the full suite of downhole logs is not available at Site 960 (Table 1). Both Holes 960A and 960C were logged, although only data from $960 \mathrm{~A}$ are used in this study. Hole $960 \mathrm{~A}$ was logged from 73 to $361 \mathrm{mbsf}$. Because of borehole washout, the sonic data are of poor quality and have not been processed, but bulk density, porosity, and resistivity data are available (Fig. 11). To cover the upper 73 mbsf where logging data were not available, bulk density and porosity data from core measurements were used. The core physical properties and logging data sets were merged at $85 \mathrm{mbsf}$, after filtering and smoothing as described above. Using the methods outlined above, the porosity data were converted to velocity using the equations of Wood (1941) and Wyllie et al. (1956). For Wood's (1941) equation, the pore fluids velocity and density were set to $1.50 \mathrm{~km} \mathrm{~s}^{-1}$ and $1.03 \mathrm{~g} \mathrm{~cm}^{-3}$, respectively. The matrix density was determined from averaging the grain densities measured in the physical properties laboratory for Site 960 , which gave a value of $2.599 \mathrm{~g} \mathrm{~cm}^{-3}$. The matrix velocity was set to $3.0 \mathrm{~km} \mathrm{~s}^{-1}$ for both the Wood and Wyllie et al. equations. Figure 12 shows the velocities calculated using the two methods, and a weighted mean ve- 
Hole 959D

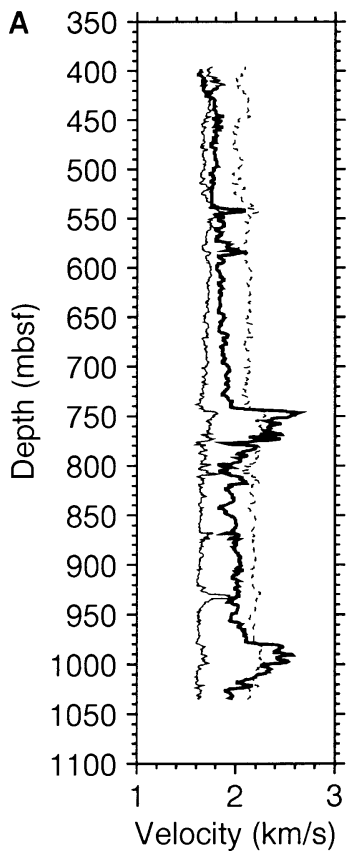

Figure 9. A. Observed velocity from the sonic log at Hole 959D (bold line), compared to the velocity calculated from porosity using the equations of Wood (1941) (thin line) and Wyllie et al. (1956) (dashed line). B. Observed velocity from the sonic log at Hole 959D (bold line), compared to the velocity calculated from a weighted average of the Wood and Wyllie et al. velocities (thin line).

locity (as described above), which was used in subsequent calculations.

Once the pseudo-velocity log had been calculated, the logs were converted to two-way traveltime (TWT) using the pseudo-velocity $\log$, and resampled with a 4-ms-sample interval. The bulk density and pseudo-velocity log were then multiplied together to give a log of acoustic impedance, and the reflection coefficient was calculated (Fig. 13). The reflection coefficient series was then convolved with the seafloor reflection wavelet to produce a synthetic seismogram (Fig. 13), which was then compared to multichannel seismic Line MT02 where it crossed Site 960 (Fig. 14). From Figure 14, it can be seen that the synthetic seismogram and the recorded multichannel profile have different frequency contents. This has arisen because the source wavelet used to derive the synthetic seismogram was taken from the single-channel seismic data, which has a higher frequency content than the multichannel data.

The synthetic seismogram shows the main features as seen on the recorded seismic data, with one strong reflector that corresponds to acoustic basement (Fig. 14). Examination of the logs shows this reflector to be correlated to two sharp increases in velocity at 160 and $200 \mathrm{mbsf}$ (Fig. 12). The bulk density decreases at $160 \mathrm{mbsf}$, then increases sharply at $200 \mathrm{mbsf}$ (Fig. 11). From the lithologic column from Site 960 the reflection at $160 \mathrm{mbsf}$ can be attributed to the boundary between middle Miocene chalk, claystone, and porcellanite and lower Eocene chert (Mascle, Lohmann, Clift, et al., 1996). This is the boundary between lithologic Subunits IIA and IIB.

The second increase in velocity, and bulk density, at $200 \mathrm{mbsf}$ can be attributed to the first occurrence of calcareous and quartz sandstones of Coniacian age at the top of lithologic Subunit IVB (Mascle,

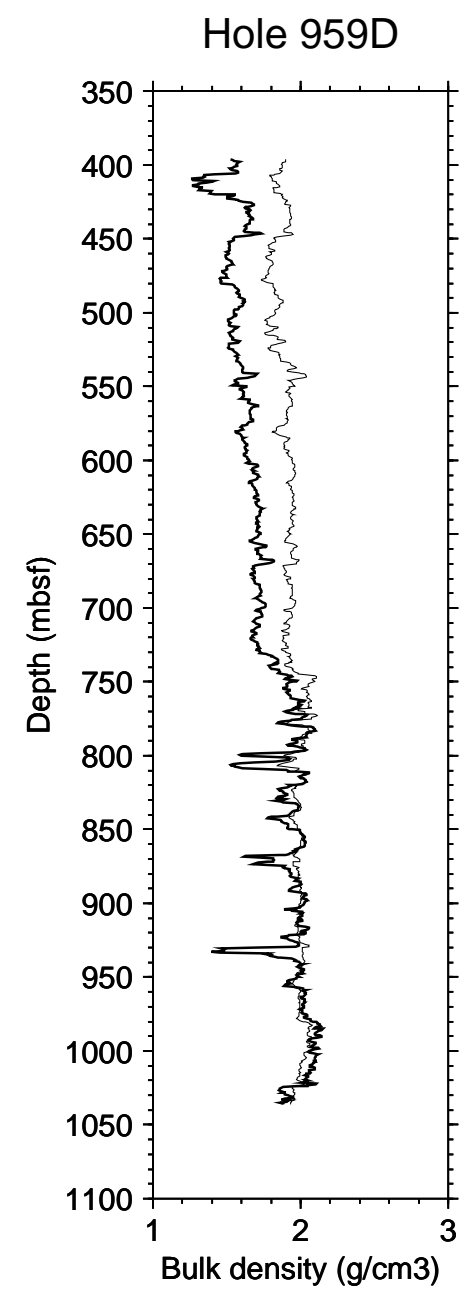

Figure 10. Observed bulk density log from Hole 959D (bold line), compared to the bulk density calculated from the porosity log (thin line).

Lohmann, Clift, et al., 1996). As these two reflectors are only $40 \mathrm{~m}$ (approximately $0.05 \mathrm{~s}$ TWT) apart, they cannot be distinguished separately on the synthetic seismogram or the recorded multichannel seismic data. Below acoustic basement, no clear reflectors can be seen.

\section{SITE 962}

Site 962 is the most westerly site drilled during Leg 159 (Fig. 1) and is located on one of the minor ridges that extend to the southwest of the CIGMR. These elongate ridges are thought to represent the continuation of the Romanche Fracture Zone from the CIGMR toward the Mid-Atlantic Ridge. Site 962 is one of the originally proposed sites (IG3), so this site was included in the single-channel seismic survey at the beginning of the leg. Two lines were shot across the site (Fig. 1), IG3-2 and IG3-3, and these are shown in Figure 15. Unfortunately, the seismic data are very noisy along these two lines and it is difficult to locate acoustic basement close to the site because the amplitude of the basement reflection appears to diminish in this region (Fig. 15).

Logging at Site 962 was severely hindered by poor borehole conditions, and the only logs obtained that are relevant to this study were 

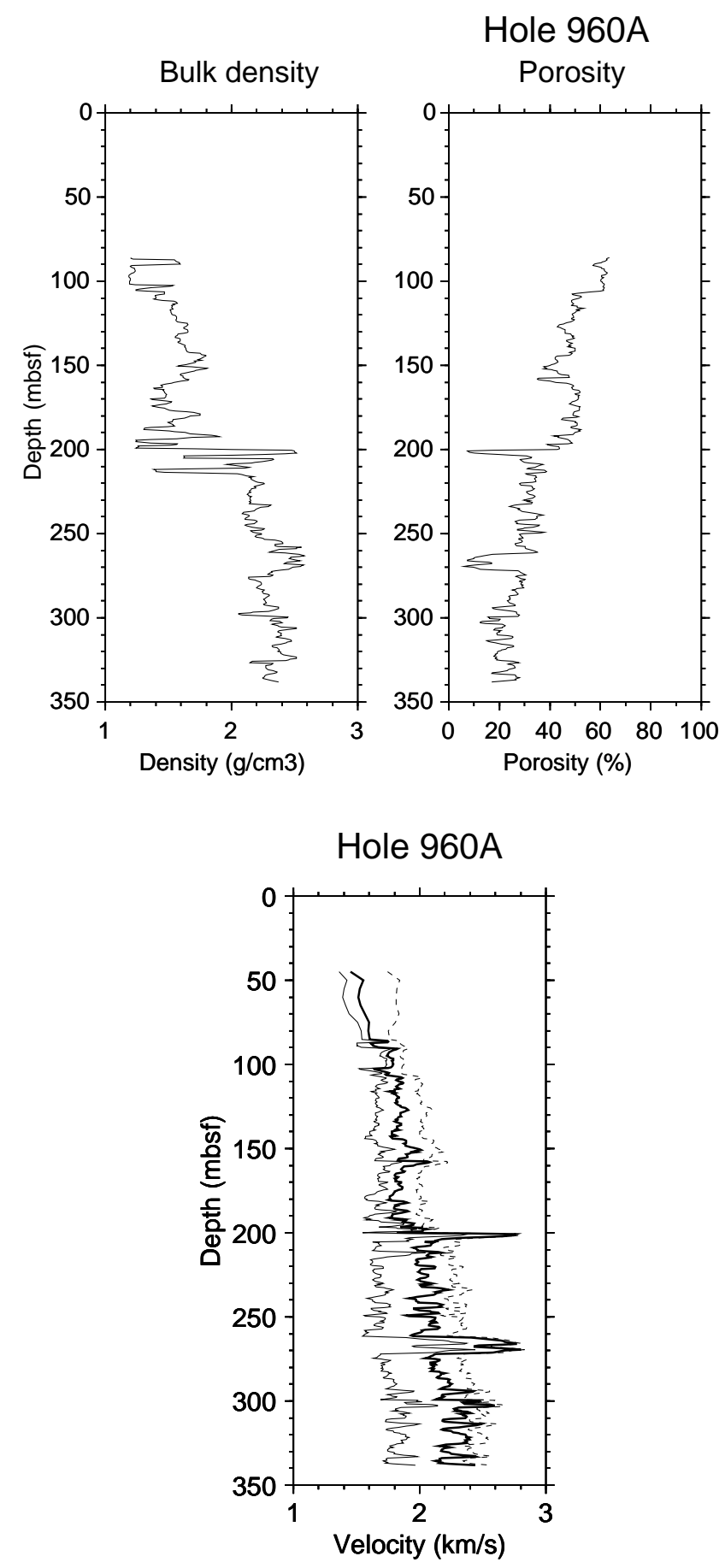

Figure 12. Pseudo-velocity logs calculated from porosity using the equations of Wood (1941) (thin line) and Wyllie et al. (1956) (dashed line). Bold line corresponds to the weighted average of the two calculated velocity logs.

resistivity and porosity logs from 162 to $328 \mathrm{mbsf}$ in Hole 962D (Table 1; Fig. 16). As a porosity log was available for the site it was possible to calculate both bulk density and sonic velocity logs from the porosity log. Because the logging data were only available below 162 mbsf, physical properties porosity measurements from Holes 962B and 962D were used to determine the porosity of the upper part of the section. Because of poor recovery between 80 and $150 \mathrm{mbsf}$ in

\section{Resistivity}

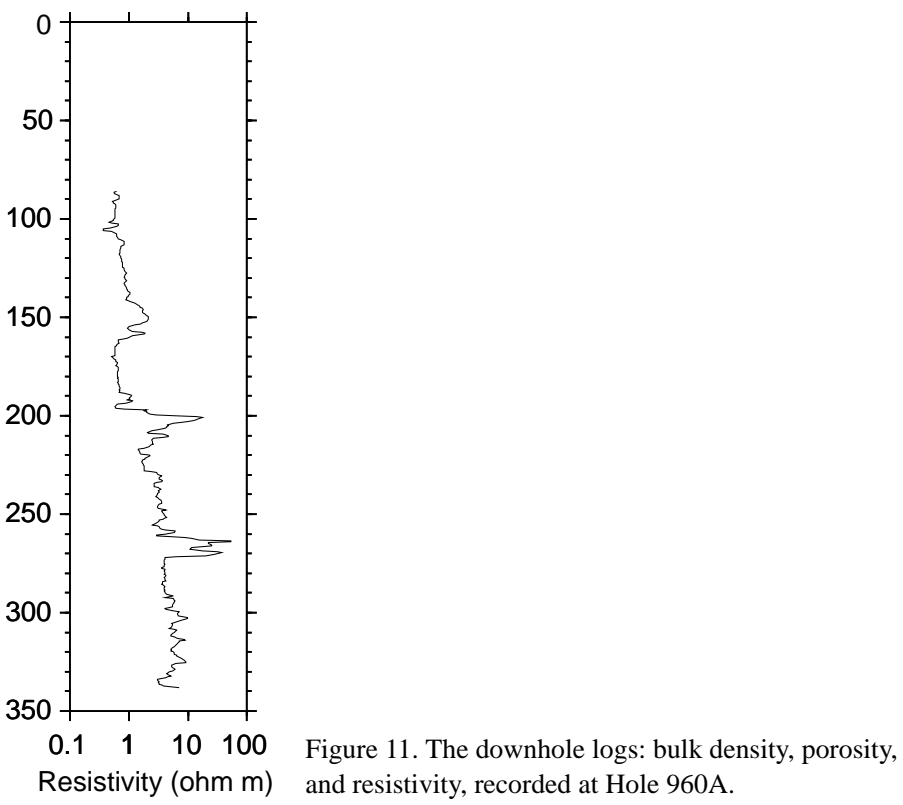

Hole 962D, porosity measurements are sparse over this interval. Unlike the other sites studied, the physical properties data were not smoothed or resampled at this site, although the downhole logs were smoothed and resampled every $50 \mathrm{~cm}$. The physical properties and downhole logging porosities were merged at $190 \mathrm{mbsf}$ (Fig. 17).

From the porosity log, a pseudo-velocity log was calculated using the equations of Wood (1941) and Wyllie et al. (1956), and applying a weighed average to the resulting velocities (see above) (Fig.18A). The pore fluid and matrix velocities were set to 1.50 and $3.00 \mathrm{~km} \mathrm{~s}^{-1}$ respectively, while the pore fluid and matrix densities were set at 1.03 and $2.69 \mathrm{~g} \mathrm{~cm}^{-3}$. The matrix density was determined by averaging the grain densities measured in the physical properties laboratory for Holes 962B and 962D. The bulk density was determined from the porosity log using the equation given above and assuming the same densities as used in the velocity calculations (Fig. 18B).

Both logs show an increase in calculated value at $65 \mathrm{mbsf}$, and this corresponds to the transition between the lower Miocene claystones and porcellanites of lithologic Subunit IIA and the claystones, manganese hardgrounds, and sandstones of unknown age in lithologic Subunit IIB. The velocity and bulk density then increase to $120 \mathrm{mbsf}$, the base of lithologic Subunit IIC. Below this depth, into the claystones, sandstones, and limestones of lithologic Unit III, the velocity and bulk density decrease.

Using the calculated velocity log, the velocity and bulk density logs were converted from depth to TWT. The logs were then resampled with a sample interval of $4 \mathrm{~ms}$ before being multiplied to give a $\log$ of acoustic impedance (Fig. 19). From the acoustic impedance log the reflection coefficient was calculated and this was convolved with a seabed reflection wavelet to produce a synthetic seismogram (Fig. 19). The synthetic seismogram shows a band of bright reflections from 0.08 to $0.18 \mathrm{~s}$ TWT. The synthetic seismogram was then spliced into the two single-channel seismic lines crossing Site 962, Lines IG3-2 and IG3-3, in the appropriate positions (Fig. 20). Because of the poor quality of the seismic data, it is difficult to determine the goodness of fit of the synthetic seismograms. The synthetic seismogram appears to fit well the observed data on Line IG3-2, but the acoustic basement reflection appears to be too early on the syn- 


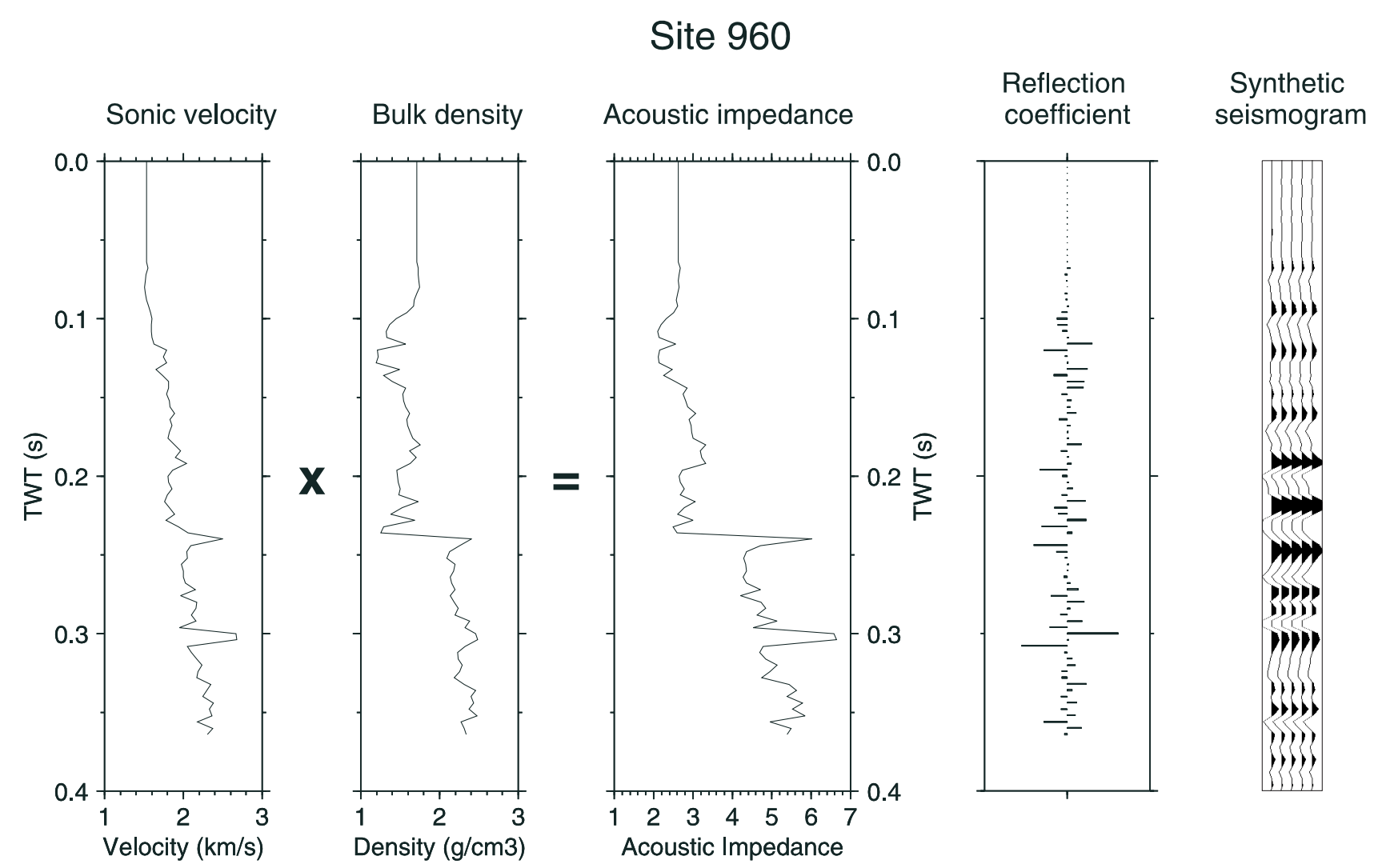

Figure 13. Calculated sonic velocity and bulk density logs from Hole 960A. The logs are derived from combining downhole logging and physical properties (above $85 \mathrm{mbsf}$ ) data. Multiplication of these logs gives the log of acoustic impedance from which the reflection coefficient and synthetic seismogram are calculated. The source wavelet used is shown in Figure 3.

thetic compared to Line IG3-3 (Fig. 20). This may be caused by Line IG3-3 not crossing Site 962 exactly. The acoustic basement reflection at Site 962 is, therefore, caused by the acoustic impedance contrasts between lithologic Subunits IIA, IIB, and lithologic Unit III. As these two interfaces are only $55 \mathrm{~m}$ apart, it is not possible to distinguish between the two individual reflections because of interference of the reflected seismic wavelets.

\section{CONCLUSIONS}

The integration of downhole logging and physical properties measurements has allowed the calculation of synthetic seismograms that can then be compared to the recorded seismic data over the sites. The general fit between the observed seismic data and the calculated synthetic seismograms is good for all three sites modeled: Sites 959, 960, and 962. The best results were achieved for Hole 959D, the deepest hole, where several reflectors were modeled.

The conversion of downhole logs from resistivity to porosity and porosity to bulk density and velocity was also successful, although this highlighted the problems of making assumptions regarding parameters such as matrix density and matrix velocity, which were assumed to be constant regardless of lithologic changes. This caused misfits between the calculated and observed bulk densities and velocities where the averaged matrix values were clearly an over- or underestimation. Synthetic seismograms calculated using the pseudovelocity and bulk density logs also showed a reasonably good fit to the observed seismic data. This highlights the usefulness of this technique where the full suite of downhole logs are not available.

The synthetic seismogram calculated for Hole 959D shows that major seismic reflectors may not always correspond to lithologic boundaries identified in the cores, a feature that should be considered carefully in any subsequent seismic stratigraphic analysis over the Deep Ivorian Basin.

\section{ACKNOWLEDGMENTS}

Thanks to Captain Ed Oonk and the crew of the JOIDES Resolution, along with ODP technical staff, for their support and cooperation during Leg 159. Dennis Graham and Dwight Mossman are acknowledged for their help in the Underway Geophysics Laboratory. Carlos Gonçalves and Lee Ewert from the Borehole Research Group at Leicester University provided help and information on the downhole logging data. The author's participation in ODP was funded by the Natural Environment Research Council (NERC), United Kingdom.

\section{REFERENCES}

Archie, G.E., 1942. The electrical resistivity $\log$ as an aid in determining some reservoir characteristics. Trans. Am. Inst. Min. Metall. Pet. Eng., 146:54-62.

Basile, C., Mascle, J., Sage, F., Lamarche, G., and Pontoise, B., 1996. Precruise and site surveys: a synthesis of marine geological and geophysical data on the Côte d'Ivoire-Ghana Transform Margin. In Mascle, J., Lohmann, G.P., Clift, P.D., et al., Proc. ODP, Init. Repts., 159: College Station, TX (Ocean Drilling Program), 47-60.

Edwards, R.A., and Shipboard Scientific Party, 1996. Underway geophysics. In Mascle, J., Lohmann, G.P., Clift, P.D., et al., Proc. ODP, Init. Repts., 159: College Station, TX (Ocean Drilling Program), 61-62.

Mascle, J., Lohmann, G.P., Clift, P.D., et al., 1996. Proc. ODP, Init. Repts., 159: College Station, TX (Ocean Drilling Program). 
Nobes, D.C., Villinger, H., Davis, E.E., and Law, L.K., 1986. Estimation of marine sediment bulk physical properties at depth from seafloor geophysical measurements. J. Geophys. Res., 91:14033-14043.

Von Herzen, R.P., Francis, T.J.G., and Becker, K., 1983. In situ large-scale resistivity of ocean crust, Hole 504B. In Cann, J.R., Langseth, M.G., Honnorez, J., Von Herzen, R.P., White, S.M., et al., Init. Repts. DSDP, 69: Washington (U.S. Govt. Printing Office), 237-244.

Wilson, W.D., 1960. Speed of sound in seawater as a function of temperature, pressure and salinity. J. Acoust. Soc. Am., 32:641-644.

Winsauer, W.O., Shearing, H.M., Jr., Masson, P.H., and Williams, M., 1952. Resistivity of brine saturated sands in relation to pore geometry. $A A P G$ Bull., 36:253-277.
Wood, A.B., 1941. A Textbook of Sound: London (G.L. Bell).

Wyllie, M.R.J., Gregory, A.R., and Gardner, L.W., 1956. Elastic wave velocities in heterogeneous and porous media. Geophysics, 21:41-70.

Date of initial receipt: 20 September 1996

Date of acceptance: 30 April 1997

Ms 159SR-028

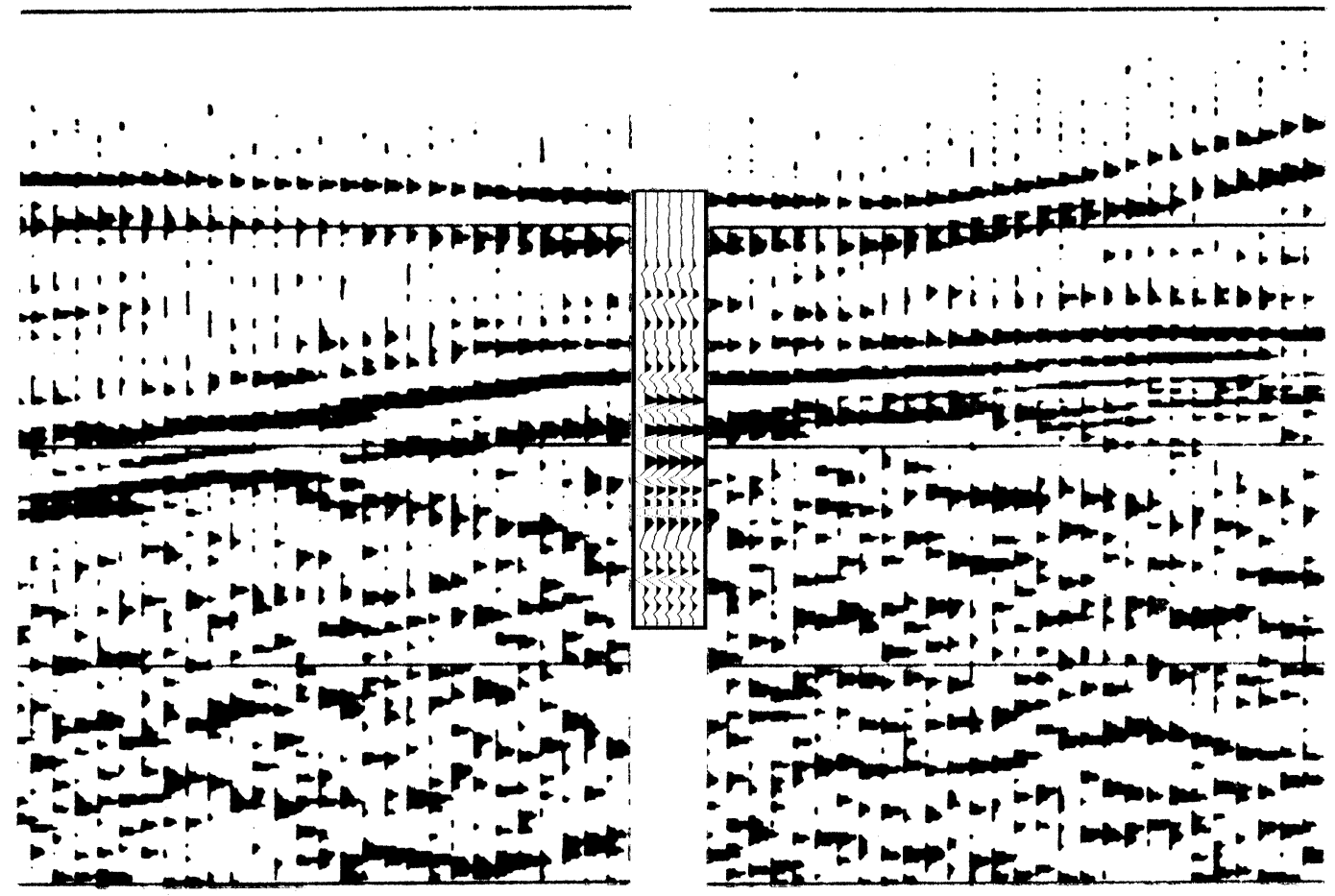

Figure 14. Synthetic seismogram calculated for Hole 960A spliced into the crossing multichannel seismic reflection profile MT02 at the appropriate location. The seabed reflection is not included in the synthetic seismogram. 


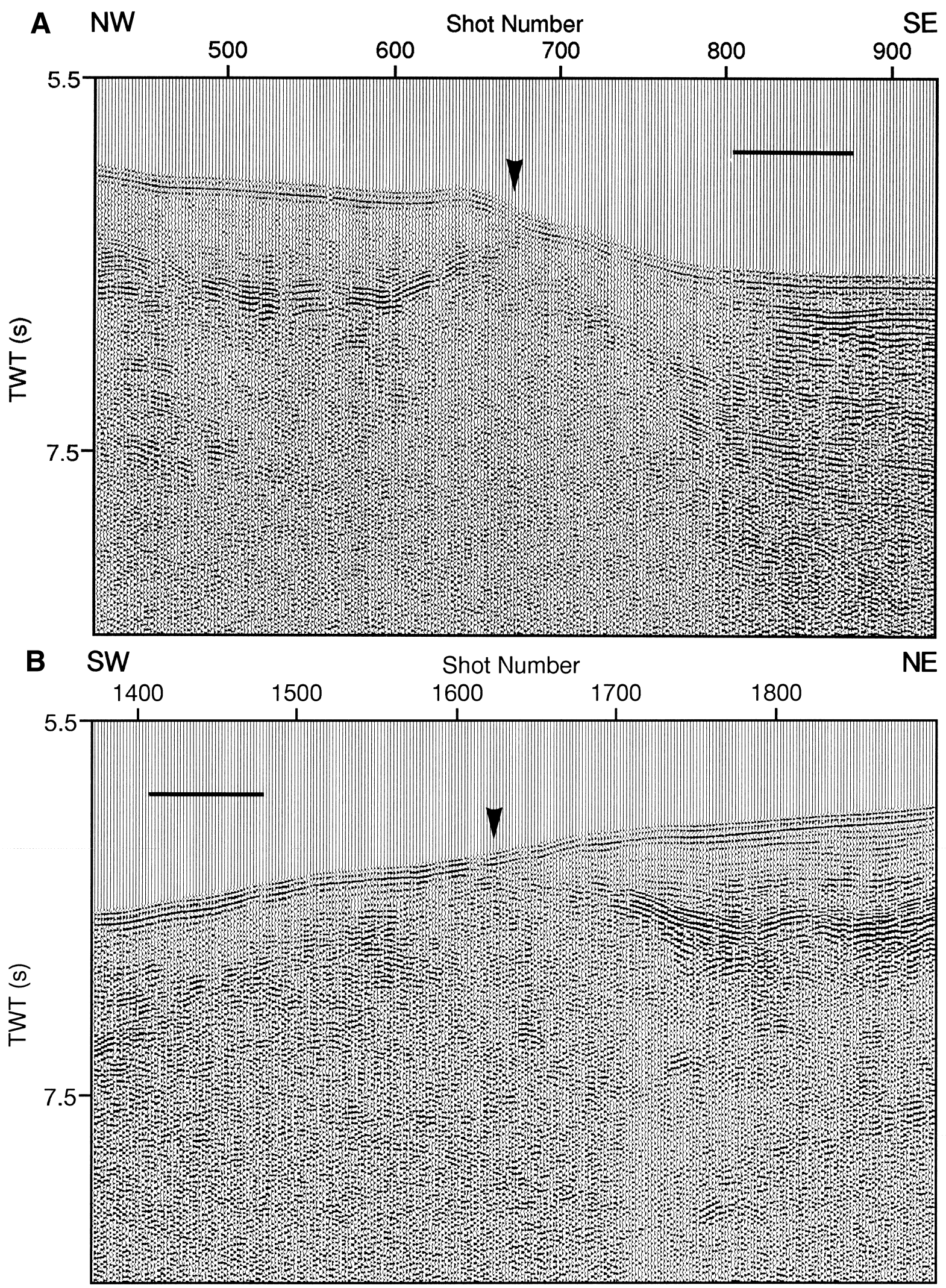

Figure 15. Single-channel seismic reflection profiles collected at the beginning of Leg 159 over Site 962 . For processing details see text. Arrow marks the location of Site 962. A. Line IG2-2. B. Line IG2-3. For line locations see Figure 1. Horizontal scale bar $=5 \mathrm{~km}$. 
Hole 962D
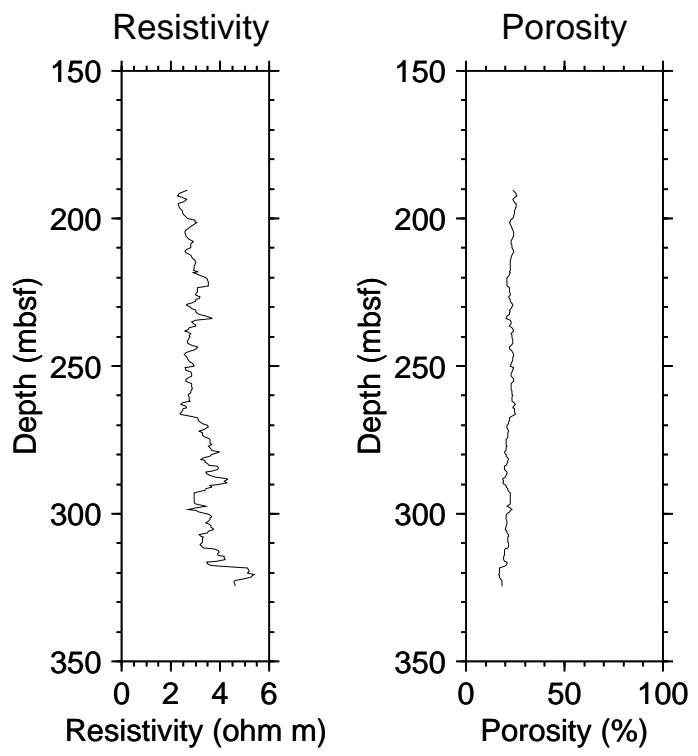

Figure 16. Resistivity and porosity downhole logs recorded at Hole 962D.

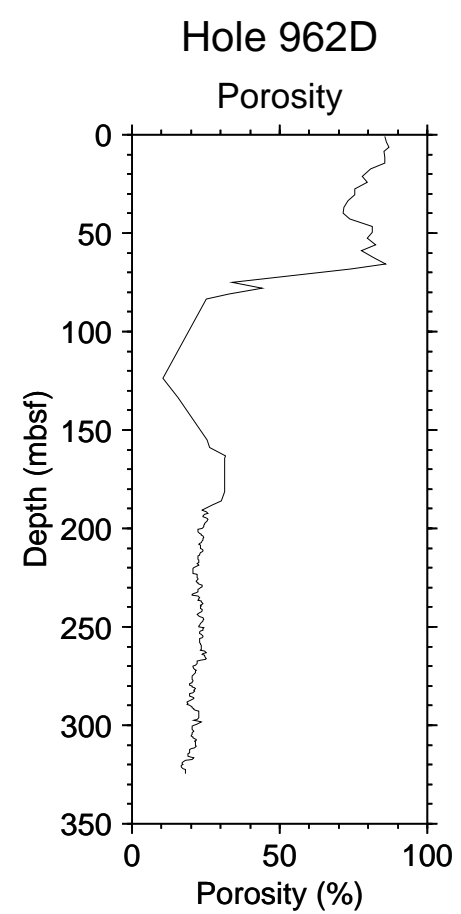

Figure 17. Porosity log from Hole 962D derived from combining physical properties (above $190 \mathrm{mbsf}$ ) and downhole logging data.

\section{Hole 962D}
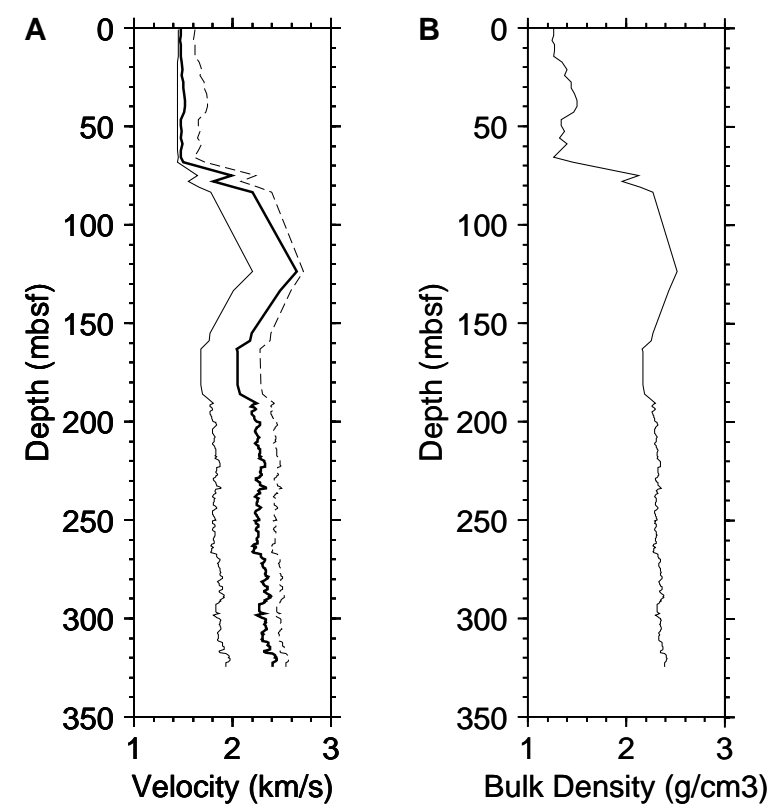

Figure 18. Pseudo-velocity and bulk density logs calculated from the porosity $\log$ for Hole 962D. A. Velocity calculated using Wood's (1941) equation (thin line), velocity calculated using Wyllie et al.'s (1956) equation (dashed line), and a weighted average of these two calculated velocities (bold line). B. Calculated bulk density. 


\section{Site 962}

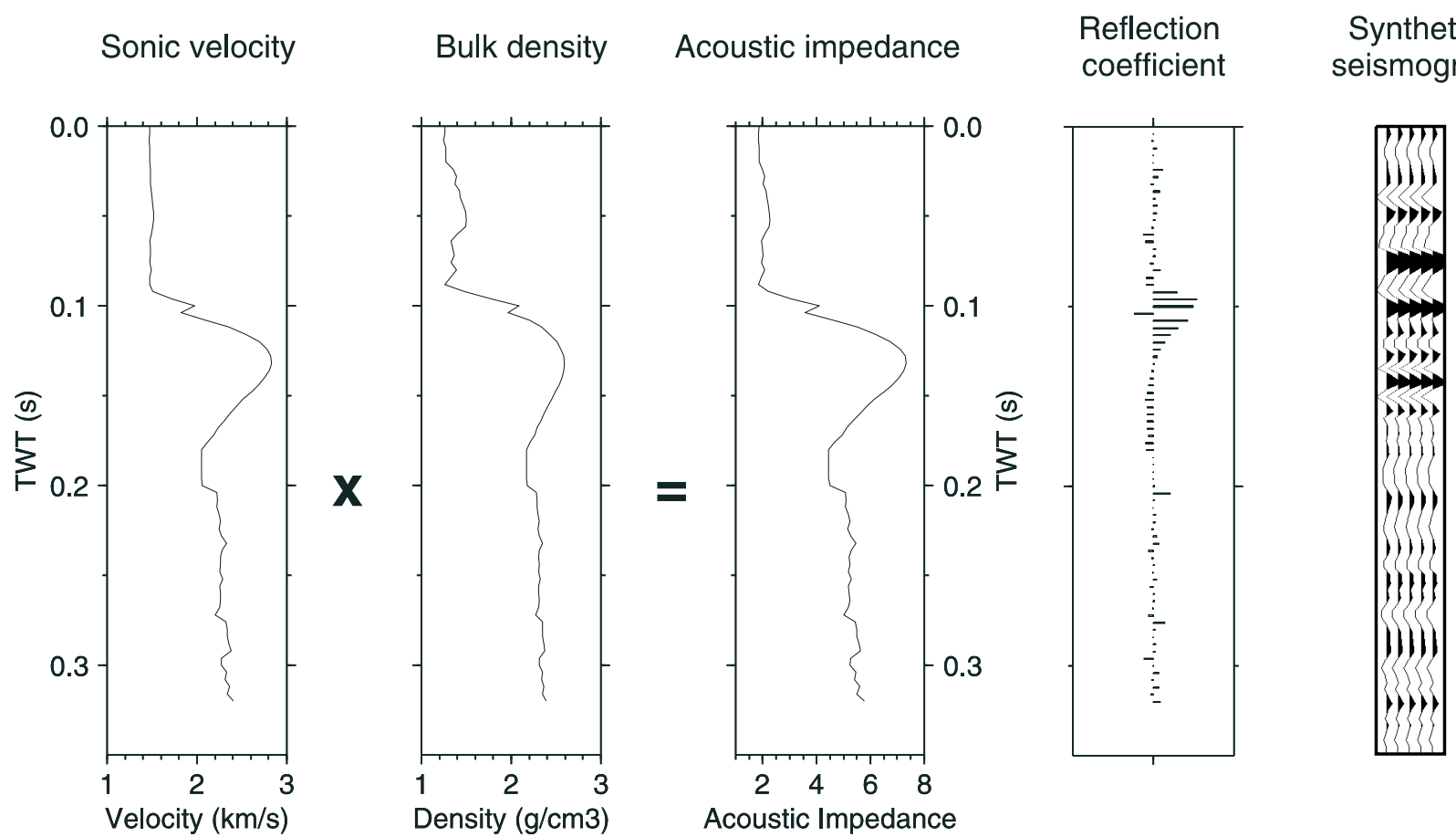

Figure 19. Calculated sonic velocity and bulk density logs from Hole 962D. Multiplication of these logs gives the log of acoustic impedance from which the reflection coefficient and synthetic seismogram are calculated. The source wavelet used is shown in Figure 3 .

A

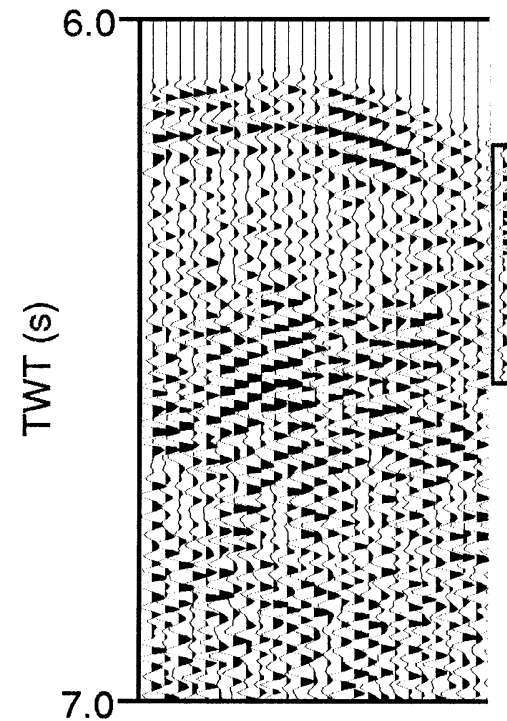

Site 962

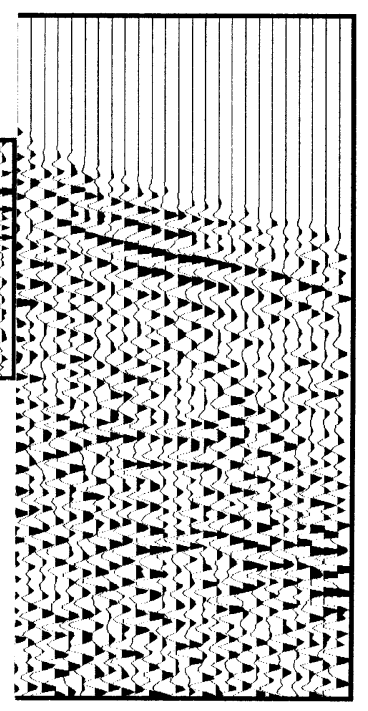

B

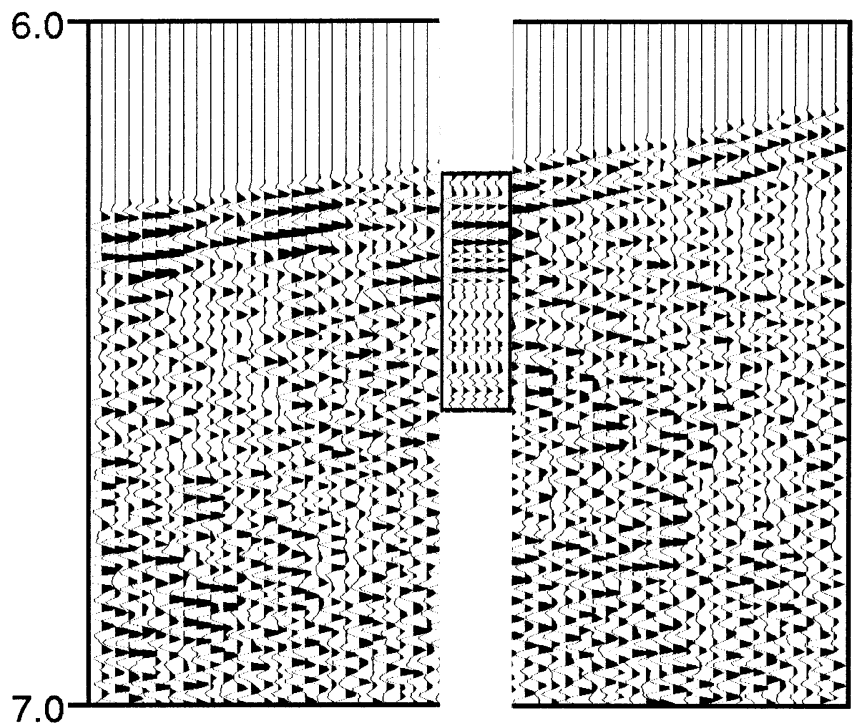

Figure 20. Synthetic seismogram calculated for Hole 962D, spliced into the crossing single-channel seismic reflection profiles at the appropriate locations. The seabed reflection is not included in the synthetic seismogram. A. Line IG3-2. B. Line IG3-3. 